\title{
Increasing the accessibility, acceptability and use of the IUD in Gujarat, India
}

\author{
M.E. Khan \\ Population Council \\ Sitanshu Sekhar Kar \\ Vikas Kishor Desai \\ Pratibha Patel \\ B.P. Itare
}

See next page for additional authors

Follow this and additional works at: https://knowledgecommons.popcouncil.org/departments_sbsr-rh

Part of the Demography, Population, and Ecology Commons, International Public Health Commons, Maternal and Child Health Commons, and the Public Health Education and Promotion Commons How does access to this work benefit you? Let us know!

\section{Recommended Citation}

Khan, M.E., Sitanshu Sekhar Kar, Vikas Kishor Desai, Pratibha Patel, B.P. Itare, and Sandhya Barge. 2008. "Increasing the accessibility, acceptability and use of the IUD in Gujarat, India," FRONTIERS Final Report. Washington, DC: Population Council. 


\section{Authors}

M.E. Khan, Sitanshu Sekhar Kar, Vikas Kishor Desai, Pratibha Patel, B.P. Itare, and Sandhya Barge 


\title{
Increasing the Accessibility, Acceptability and Use of the IUD in Gujarat, India
}

\author{
Frontiers in Reproductive Health Program (FRONTIERS), \\ Population Council \\ M.E. Khan \\ Sitanshu Sekhar Kar \\ Department of Health and Family Welfare, Government of Gujarat \\ Vikas Kishor Desai \\ Pratibha Patel \\ B. P. Itare
}

Center for Operations Research and Training, Vadodara

Sandhya Barge

May 2008

This study was funded by the generous support of the American people through the United States Agency for International Development (USAID) under the terms of Cooperative Agreement No. HRN-A- 00-9800012-00, In-house Project No. 5800.53105 and Subaward AI06.77A. The contents are the responsibility of the FRONTIERS Program and do not necessarily reflect the views of USAID or the United States Government.

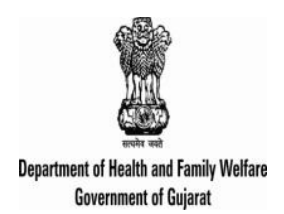




\section{EXECUTIVE SUMMARY}

Despite the many advantages of the IUD as a method of family planning, it generally suffers from unpopularity worldwide, with the exception of a few countries like China, Egypt, Mexico and Turkey. The scenario in India is the same, with less than two percent of currently women adopting the IUD as a method of contraception. The USAID-funded FRONTIERS Program of the Population Council, in collaboration with the Department of Health \& Family Welfare, Government of Gujarat and the Center for Operations Research and Training, Vadodara, conducted an operations research study to test the hypothesis that improving the demand for the IUD and simultaneously strengthening the technical competencies and counseling skills of the providers, use of the IUD use would increase.

A pre and post intervention design with no control group was used. The study was carried out in both rural and urban areas with a population of 300,000 in Vadodara District, Gujarat. The package of interventions included: (a) strengthening counseling and technical skills of providers; (b) an educational campaign using field-tested behavior change communication (BCC) educational materials; (c) strengthening provision of IUD services in selected sub-centers and PHC; and (d) making the programmatic environment more supportive of spacing methods. The impact of the intervention was evaluated nine months after introduction of the interventions.

Knowledge of providers on the critical steps for providing IUD services increased significantly, from 5 percent to 40 percent, and the proportion of women having poor knowledge (score of $<7$ out of 29) decreased significantly from 81 to 47 percent. Though the proportion believing in myths decreased significantly from the baseline, their prevalence was still high at endline. The proportion of IUD users who reported the quality of IUD services received to be good (score of $\geq 25$ out of 34 ) increased from 26 percent to 73 percent. A majority ( 92 percent) of providers used the IEC materials developed during the project when counseling clients and 95 percent of them stated that their performance improved because of the IEC materials. Due to continuous monitoring and supportive supervision by the medical officers, over-reporting of IUD cases decreased significantly from 42 percent to 2 percent. Comparison of month- wise IUD insertion rates during the intervention period (2007), compared with 2006 showed significant improvement after adjusting for over reporting.

A cost analysis shows that the additional cost of carrying out educational activities and strengthening provision using this model is approximately \$3.37 per IUD user and to strengthen IUD services in one facility is approximately $\$ 74$ per facility. These costs are for the pilot project; if the model is scaled up the per-site cost will be lower because of the scale of expansion. These are affordable costs and need serious consideration by the Family Welfare Department.

Demand generation activities and provision of good quality IUD services, together with a supportive programmatic environment when carried out simultaneously showed increased acceptance of the IUD. The intervention could be easily integrated into the existing system. A sustained and coherent IEC campaign is required to remove myths; the IEC and counseling aids developed for the study have been well accepted by health care providers, clients and national and state government officials. 


\section{TABLE OF CONTENTS}

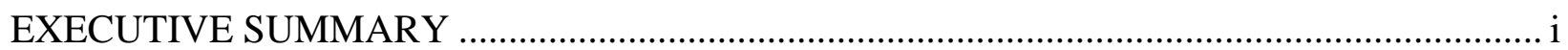

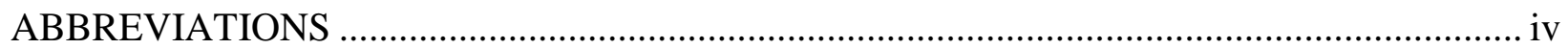

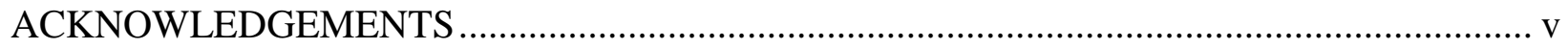

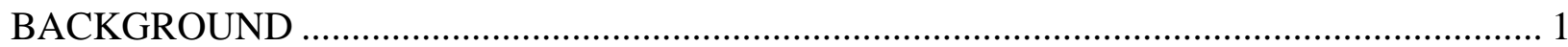

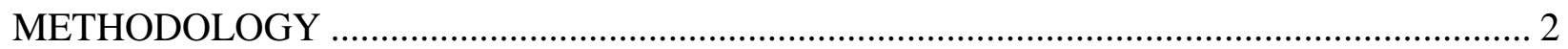

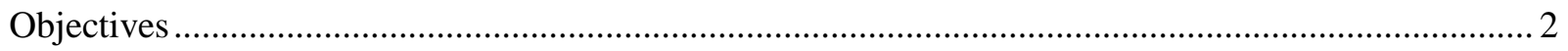

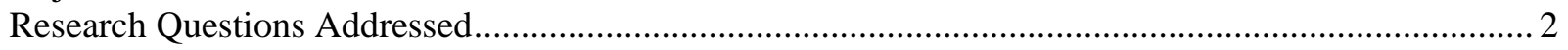

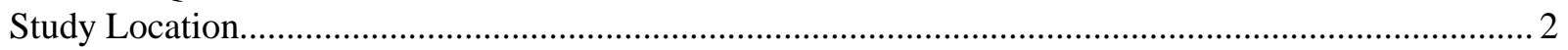

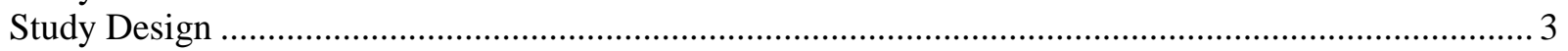

Dependent and Process Variables........................................................................................................ 3

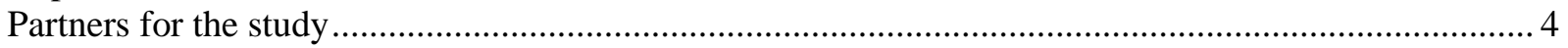

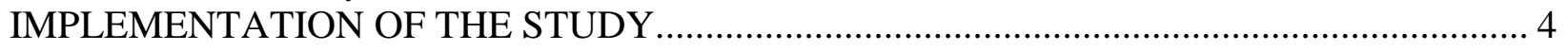

Diagnostic and Preparatory Phase …………………………………………………………… 4

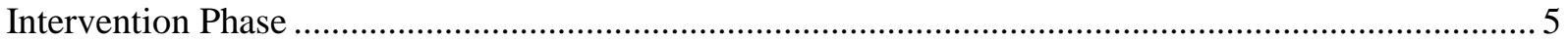

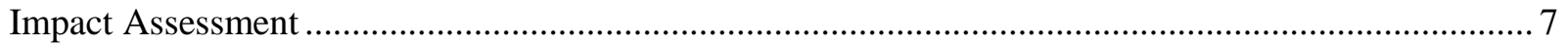

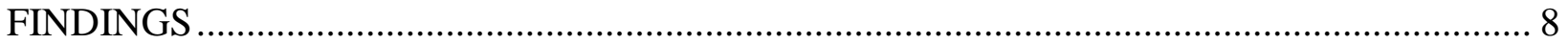

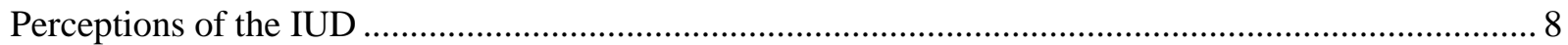

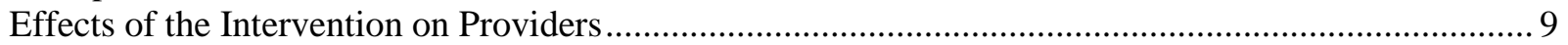

Effects of the Intervention on Clients............................................................................................. 14

Reported Quality of IUD services by Users ………………………………………………... 15

Validity of the Service Statistics during the Intervention.................................................................. 17

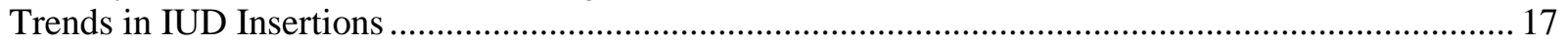

Perception of Pharmacists about the IUD .................................................................................. 19

Economic Analysis of the Intervention Model...…………………………………………....... 19

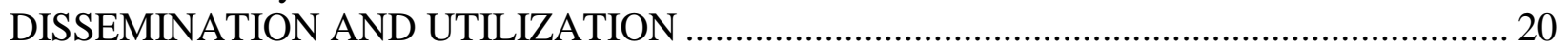

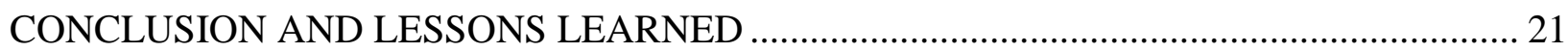

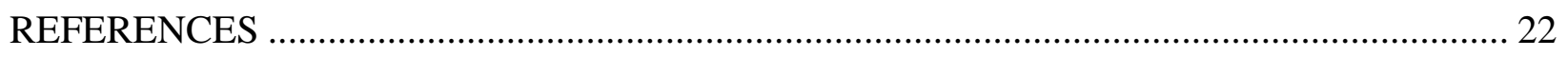

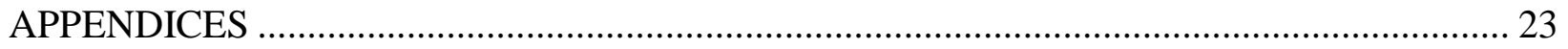

Appendix 1: Profile of Health Care Providers................................................................................ 23

Appendix 2: Parameters Considered to Assess Knowledge of HCPs on IUD ..................................... 24

Appendix 3:Selected Parameters considered to assess the Knowledge on IUD Insertion of HCPs.......25

Appendix 4: Logical Steps to Assess the Knowledge of HCPs on IUD Removal .................................2 26

Appendix 5:Parameters considered to Assess the Attitude of HCPs before and after Intervention ........22

Appendix 6: Household Characteristics of Women in Study Population............................................... 28

Appendix 7:Parameters Considered to Assess Knowledge of Women before and after the Intervention29

Appendix 8: Background Characteristics of IUD Users....................................................................... 30

Appendix 9:Assessment of Quality of IUD Services by Interviewing IUD Acceptors.......................... 31 


\section{LIST OF TABLES}

Table 1: Number of HCPs Trained during Intervention .................................................... 6

Table 2: Total Numbers of IEC Materials Distributed During the Intervention........................... 6

Table 3: Sample Coverage of Baseline and Endline Surveys ..................................................... 7

Table 4: Change in Knowledge About IUD Among the HCPs ............................................... 9

Table 5: Selected Indicators to Assess Counseling Skills of HCP .......................................... 11

Table 6: Knowledge of HCPs about Selected Critical Steps for IUD Insertion and Removal ..... 12

Table 7: Improvement in Knowledge about IUD among Women........................................... 14

Table 8: Change in Level of IUD Knowledge Among Women ............................................ 15

Table 9: Change in Myths Related to IUD Among Women................................................... 15

Table 10: Reported Quality of Care by IUD acceptors (Mean Score \pm SD) ........................... 16

Table 11: Costs Incurred during Implementation of Intervention ............................................ 19

\section{LIST OF FIGURES}

Figure 1: Level of IUD Knowledge Among HCPs Before and After the Intervention ............... 10

Figure 2: Level of Counseling skill of HCPs after Intervention ............................................... 11

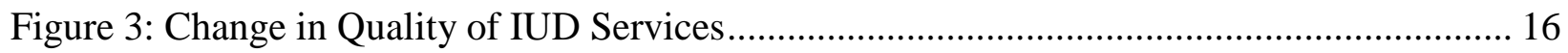

Figure 4: IUD Insertion Rate in Urban Area in 2006-07 ................................................... 18

Figure 5: IUD Insertion Rate in Rural Study Area in 2006-07 .............................................. 18 


\section{ABBREVIATIONS}

$\begin{array}{ll}\text { AWW } & \text { Anganwadi Workers } \\ \text { ANM } & \text { Auxiliary Nurse Midwife } \\ \text { BCC } & \text { Behavior Change Communication } \\ \text { FGD } & \text { Focus Group Discussion } \\ \text { HCPs } & \text { Health Care Providers } \\ \text { IEC } & \text { Information Education and Communication } \\ \text { IUD } & \text { Intra Uterine Device (Copper T380A) } \\ \text { LHV } & \text { Lady Health Visitors } \\ \text { MOHFW } & \text { Ministry of Health and Family Welfare } \\ \text { MOIC } & \text { Medical Officer In Charge } \\ \text { NFHS } & \text { National Family Health Survey } \\ \text { OR } & \text { Operations Research } \\ \text { PHC } & \text { Primary Health Centers } \\ \text { PHN } & \text { Public Health Nurse } \\ \text { SC } & \text { Sub-centers } \\ \text { VMC } & \text { Vadodara Municipal Corporation } \\ \text { USAID } & \text { United States Agency for International Development }\end{array}$




\section{ACKNOWLEDGEMENTS}

The project was a collaborative effort of the FRONTIERS Program of Population Council, the Directorate of Health and Family Welfare, Government of Gujarat. In carrying out this OR study in Vadodara, Gujarat, many people contributed in different ways. First of all we extend our special thanks to Dr. Amarjit Singh, Commissioner and Secretary of Health, Government of Gujarat for his immense interest, commitment and continued support throughout this project. We would also like to thank the Additional Medical Officer of Health, Vadodara Municipal Corporation for his active involvement and support. Our sincere gratitude is due to the CDHO, Additional District Health Officer, Vadodara, for their active participation and coordinating the IUD study in the selected study area. We are also thankful to the MOIC of Bhaili, Vernama, Asoj, Ranoli and Handod PHCs in rural area and Fatehpura, Gorwa, Navayard, Gotri, Manjalpur and Sawad VMCs in urban area for taking a keen interest and faithfully implementing this OR project in their respective health centers. We are also extremely grateful to all the PHNs, ANMs, LHVs/ supervisors, male workers and anganwadi workers whose untiring efforts had made this project a successful model.

Our appreciation also goes to the Center for Operations Research and Training (CORT), Vadodara, the organization which successfully completed the baseline and endline surveys of this OR project

Finally, we would like to acknowledge the support and help from our colleagues at the offices of the Population Council in India and USA and especially Ms. Sohini Roychowdhury and Ms.

Geetha Vaithyanathan. 


\section{BACKGROUND}

The IUD is underused in the Indian Family Planning Program and repositioning it will have several advantages. It increases choice for a long-acting and safe contraceptive to achieve optimal birth intervals (3-5 years); with the Copper T-380A, a woman can protect herself against pregnancy for up to 12 years. This is particularly attractive for those couples who have achieved their desired family size but do not want to adopt a permanent method like sterilization. The IUD is a highly effective contraceptive method (pregnancy rate $<1 \%$ ) and does not require constant attention. It does not interfere with intercourse and there is a quick return of fertility once woman stops using the method. As the IUD can be used for at least 10 years, its use will be less expensive than most temporary methods. This is an important consideration for countries where contraceptive security is an issue, such as with the Ministry of Health and Family Welfare (MOHFW).

The evidence from various projects trying to increase use of the IUD suggests several factors as conditions for success. They include providing a supportive policy environment for the repositioning of the IUD, a commitment to provide accurate information about the method to clients, eliminating myths and misconceptions about the IUD using appropriate behavior change communication (BCC), upgrading of the technical and counseling skills of health care providers, mechanisms for follow-up and resolving supply constraints to meet the emerging demand. Repositioning of the IUD requires simultaneous efforts to increase demand, ensure supply and ensuring the providers a programmatic environment where a contraceptive mix is valued and encouraged. Studies in India clearly demonstrate that in rural areas, lack of access to quality IUD services and follow-up, compounded with myths and misconceptions about the method, limited educational materials to provide accurate information about the method to clients, and provider bias against the IUD are serious barriers to IUD use (Santhya 2003, Mishra and Retherford 1999, Khan et al 1999, NFHS 2006, Gandotra and Das 1996). In addition, the national program emphasis on sterilization gives little motivation to health care providers (HCPs) to promote the IUD or other temporary contraceptive methods. In this environment, it is not surprising that temporary contraceptive method use in the country is limited to 10.2 percent and that of IUD only 1.8 percent (NFHS 2006). During the last 20 years, use of the IUD has remained low. Recently, however, the MOHFW has been trying to increase use of temporary methods; it has set up committees at the Ministry level to examine the overall strategy to strengthen BCC efforts to promote spacing methods, particularly the repositioning of the IUD. 


\section{METHODOLOGY}

\section{Objectives}

The goal of the study was to demonstrate that by simultaneously improving demand for and supply of the IUD and strengthening the technical competencies and counseling skills of the providers, IUD use could be increased. The specific objectives of the study were to:

1. Increase awareness and correct knowledge of the IUD among men and women in the reproductive age group.

2. Enhance the acceptability of the IUD among providers.

3. Increase use of the IUD by making services more accessible, and providing services of higher quality, and

4. Estimate the cost of scaling up of the intervention in larger areas.

\section{Research Questions Addressed}

The study sought to answer the following questions:

1. Does reorientation of providers and providing supportive supervision stimulate them to use the balanced counseling approach (BCS) and to offer the IUD as a safe, long-acting contraceptive?

2. Does reorientation training help in improving the quality of counseling and services?

3. Does improved community-based BCC about the IUD increase interest and intention to use the IUD as a contraceptive method?

4. Does provision of accurate information on the IUD reduce the myths and misconceptions about IUD use?

5. Does the increased awareness and knowledge of the IUD and increased accessibility to services result in its increased use?

6. Is the intervention feasible, sustainable and economically viable in the Indian context?

\section{Study Location}

The study was carried out both in rural and urban areas of Vadodara district of the state of Gujarat. The study was carried out in a population of 150,000 in rural areas spread over five Primary health centers (PHC) and in 150,000 in urban areas spread over six Vadodara Municipal Corporation (VMC) clinic areas. As the main emphasis was on improving BCC to increase the use of the IUD, the following selection criteria was used for selecting study sites:

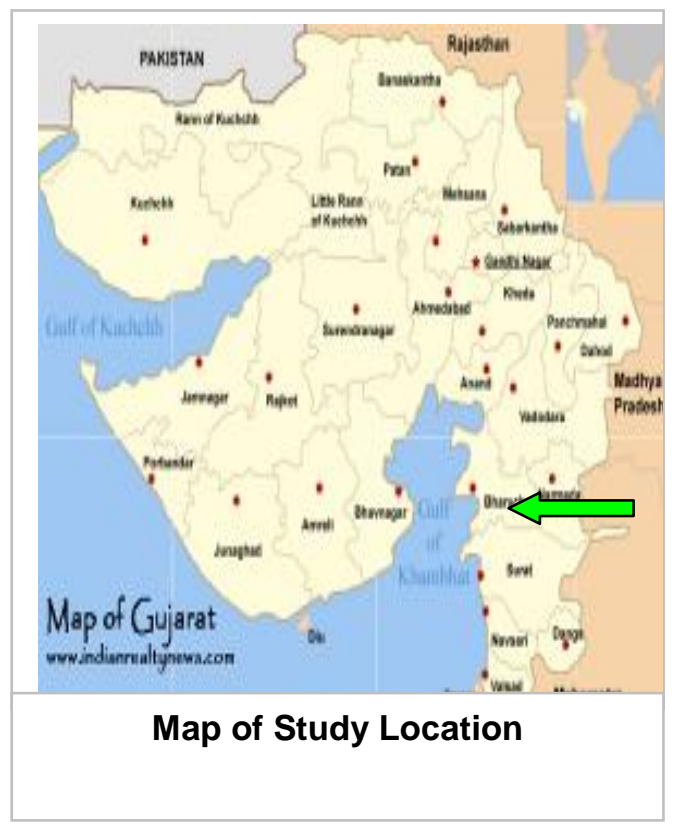


- Clinics having trained providers (ANM/LHV/Doctors) with technical competency in insertion and removal of IUDs.

- Clinics having minimum infrastructure facility, equipment and supplies to carry out screening of the clients before IUD insertion.

\section{Study Design}

An experimental pre and post survey design with no control group was used. The intervention was implemented for a period nine months. The figure below illustrates the design and the package of interventions.

Where,

\begin{tabular}{lll}
$\mathrm{O}_{1}$ & $\mathrm{X}+\mathrm{Y}+\mathrm{Z}$ & $\mathrm{O}_{2}$ \\
& 9 Months & \\
\hline
\end{tabular}

- $\mathrm{X}$ is strengthening counseling and technical skills of the providers for insertion and removal of the IUD

- $\mathrm{Y}$ is the BCC effort to educate potential users about the IUD as a safe and long-acting contraceptive method

- $\mathrm{Z}$ is strengthening the provision of IUD services in selected sub-centers, PHCs and VMC centers

- $\mathrm{O}_{1}$ is IUD service statistics over a 9-month period before the intervention and data from the baseline survey of currently married men and women

- $\mathrm{O}_{2}$ is IUD service statistics during nine months after the intervention and data from the endline survey of currently married men and women.

\section{Dependent and Process Variables}

The key dependent variable considered for the study was use of the IUD among clients. However, given the short intervention period available ( 9 months) and that behavior change is a continuous process and passes through a series of stages (e.g. pre-contemplation, contemplation, preparation, action and maintenance (Prochaska et al 1992)), a major increase in the adoption of the IUD was not expected, but instead changes in process variables were anticipated, such as increased positive perception and knowledge of the IUD at the community level and a decrease in myths about the device. Because of this, some process variables were also assessed:

1. Increased knowledge of IUD and its mode of functioning, and the duration for which IUD could prevent pregnancy among clients

2. Decrease in myths surrounding the IUD among clients

3. Improved knowledge about benefits and side effects of the IUD

4. Change in knowledge of the providers towards the IUD and its effectiveness

5. Increase in technical knowledge and counseling skills of providers about IUD and quality of services

6. Proportion of providers used of teaching aids/ IEC materials to make counseling more effective. 


\section{Partners for the study}

The study was carried out by the Department of Health and Family Welfare, Vadodara Municipal Corporation (VMC), the Government of Gujarat, in collaboration with FRONTIERS Program of Population Council and the Center for Operations Research and Training (CORT).

\section{IMPLEMENTATION OF THE STUDY}

The study was carried out in three phases:

- Diagnostic and preparatory phase

- Intervention phase

- Impact assessment and sharing of findings.

\section{Diagnostic and Preparatory Phase}

During the diagnostic and preparatory phase, selection of the study sites, review of available statistics, development of BCC materials and educational aids, and preparatory work for training of paramedics were completed. Formative research was carried out, both to understand the users' perspectives about the IUD and its use, as well as prevailing myths and misperceptions about the contraceptive. It also helped in understanding the context of contraceptive acceptability in the community. Similarly, informal discussions and Focus Group Discussions (FGDs) with providers helped in understanding providers' perspectives and their problems in promoting the IUD and personal biases against the IUD, if any. The findings were used for preparing BCC materials and counseling aids for the study areas.

Data were collected primarily using qualitative techniques (i.e., FGDs and informal discussions). The following qualitative data were collected:

- Five FGDs of providers (3 female and two male multipurpose workers)

- Twelve FGDs of potential clients (8 of women and 4 of male partners)

- Eight in-depth case studies of IUD users (4 of those who are continuing for at least one year and 4 of those who have recently discontinued)

- Four discussions with PHC/VMC physicians and district authorities.

Based on the findings of the formative research a set of behavior change communication materials (BCC) were developed.

Client leaflet: The leaflet contained information about the IUD, how it works, who can use it, advantages, side effects and myths associated with IUD use. This leaflet was used for awareness raising in the community by distributing it widely through the health workers as well as anganwadi (nutrition) workers. The messages given in the leaflets reinforced the information given by the providers during counseling sessions on the IUD. 
Provider leaflet: This leaflet helped the providers to remember the steps of IUD insertion and removal. Along with basic information, some technical details were also included so that it could be used as a quick refresher and counseling tool. Each provider (medical officer and paramedics) were given a copy to keep at the health center and refer to whenever necessary.

IUD chart: This chart provided a graphical representation of the steps of IUD insertion with the no-touch technique and removal procedure. This chart could be used as a guide to improve the quality of IUD insertion and removal.

IUD flip chart: This was a small booklet in form of a flip chart containing information that would help the providers in counseling and help illustrate the clients about IUD during their field visits. The size of the booklet was small so that the providers could easily carry it in their purse as a counseling aid.

Posters: Two posters imparting key messages about the IUD were displayed at the sub- centers (SCs), primary health centers (PHCs), Vadodara municipal corporation clinics (VMCs) and anganwadi centers of the study area to increase awareness about IUD.

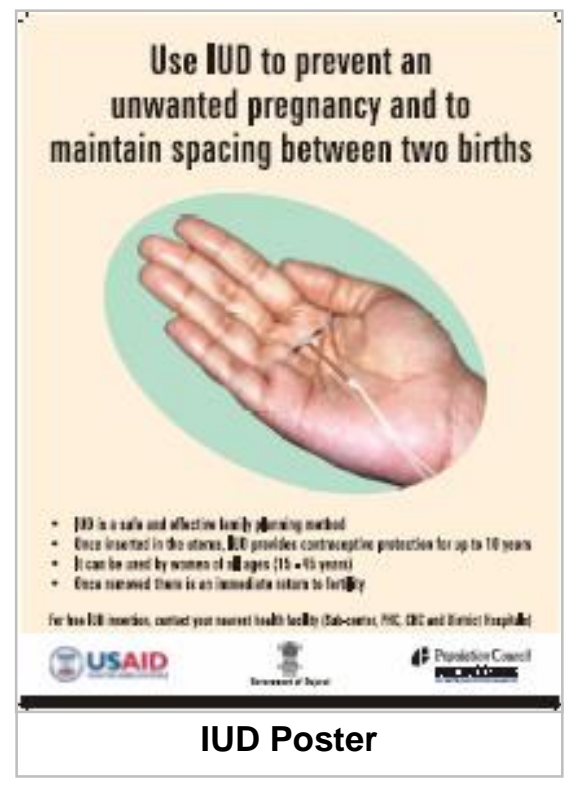

All BCC materials were field tested for language, clarity and acceptability of the massages by providers and potential clients before being finalized. On the basis of the field results, materials were modified, if required.

\section{Intervention Phase}

The intervention package included the following components and was implemented for a period of nine months.

Training of Health Care Providers: The training curriculum for providers was finalized by an expert team consisting of two Gynecologists, one Demographer, one Social Scientist cum Anthropologist and one Public Health expert. All members of the expert team had extensive experience in public health programs, training of paramedics and were

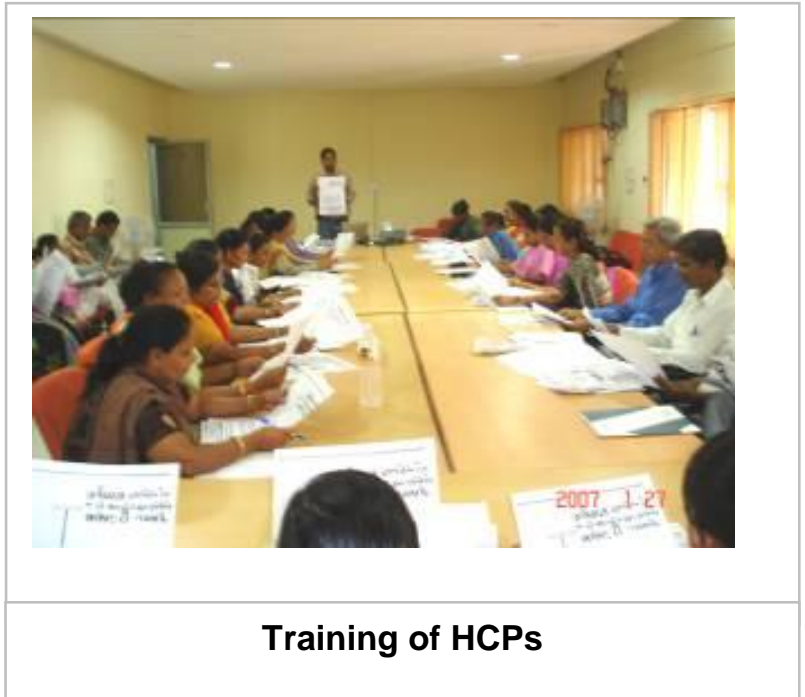
aware of the strengths and weaknesses of the system. It was decided that the paramedics would be trained first for two days and later, a one-day reorientation would be held four months after the first training. It was also decided that the medical doctors would be reoriented for a half-day and the emphasis would be on supportive supervision and counseling since they were regularly inserting IUD (in case of urban clinics) or were not providing IUD services (in the case of rural clinics with male providers). As the majority of HCPs resides in the district and commute daily 
to and from their workplace, the training was organized in Vadodara district. The training was conducted at the Vaccine Institute, which is the usual site for training of all health workers. Staff from 41 facilities (5 PHCs, 30 sub-centers and 6 VMCs) were trained, including 10 medical officers and 67 paramedical workers.

All the paramedics that participated in the study were trained in IUD insertion and removal and were regularly providing the device. Hence, the training was largely a refresher course in insertion and removal of the device (no-touch technique) and a more comprehensive training on counseling skills and use of job aids for effective communication with clients. It was also decided that the male health workers, who are mainly present in the rural areas, would also be involved in training and orientation on the IUD. The number of female paramedics, male workers and doctors who were trained in the study is

\begin{tabular}{|c|c|}
\hline \multicolumn{2}{|c|}{$\begin{array}{c}\text { Table 1: Number of HCPs Trained } \\
\text { during Intervention }\end{array}$} \\
\hline a. Two days training of paramedics & N \\
\hline ANM/FHW & 44 \\
\hline LHV/PHN/ Staff nurse & 12 \\
\hline Male workers & 10 \\
\hline b. Half day refresher training of doctors & 10 \\
\hline c. Half day orientation of paramedics & \\
\hline ANM/FHW & 44 \\
\hline LHV/PHN/ Staff nurse & 12 \\
\hline Male workers & 10 \\
\hline
\end{tabular}
given in Table 1.

Strengthening behavior change communication: Several types of communication materials and job aids for providers were provided in sufficient numbers to the respective HCPs for wide dissemination. They consisted of separate leaflets for providers and clients, job aids and counseling aids. Posters containing information on IUD were displayed at VMC/PHC/Subcenters/anganwadi centers and selected chemist shops. The total number of IEC and counseling material distributed is given in Table 2. To make counseling focused and more effective, ANMs were provided with a counseling aid in the form of a flip book on IUD.

\begin{tabular}{|l|c|c|c|c|c|c|c|}
\hline \multicolumn{7}{|c|}{ Table 2: Total Numbers of IEC Materials Distributed During the Intervention } \\
\hline & $\begin{array}{c}\text { Client } \\
\text { leaflet }\end{array}$ & $\begin{array}{c}\text { Providers } \\
\text { leaflet }\end{array}$ & $\begin{array}{c}\text { IUD } \\
\text { chart }\end{array}$ & $\begin{array}{c}\text { Pregnancy } \\
\text { Checklist }\end{array}$ & $\begin{array}{c}\text { IUD flip } \\
\text { book }\end{array}$ & $\begin{array}{c}\text { Poster } \\
\text { One }\end{array}$ & $\begin{array}{c}\text { Poster } \\
\text { Two }\end{array}$ \\
\hline Rural & 30,000 & 100 & 100 & 100 & 80 & 100 & 100 \\
\hline Urban & 21,000 & 50 & 50 & 50 & 30 & 100 & 100 \\
\hline Anganwadi Centers & 8,500 & NR & NR & NR & NR & 325 & 325 \\
\hline Total & 59,500 & 150 & 150 & 150 & 110 & 525 & 525 \\
\hline NR - Not required
\end{tabular}

As one anganwadi worker is assigned per 1,000 population, and she usually resides within the community, anganwadi workers were used to disseminate information regarding the IUD in monthly meetings. Approximately 300 anganwadi workers (170 from rural and 130 from urban areas) were involved to educate clients regarding the method and worked in collaboration with the ANMs/ FHWs. As the anganwadi worker conducts one meeting every month with the pregnant, lactating mothers and newly married women to counsel them about nutrition, safe delivery practices and family planning, a total of 300 group meetings were conducted each month in the study area with emphasis on the IUD and other family planning methods. Male workers were told to conduct group meetings with husbands and educate them about the IUD. 
Programmatic change: Given the existing program emphasis on sterilization, workers do not feel motivated enough to promote the IUD. Hence to create a positive programmatic environment where contraceptive choice is emphasized and valued, the MOICs of the clinics were requested that in monthly meeting they should carefully review the method mix being provided. The purpose of this focus was to give a signal to all the workers that the program is committed to providing all methods, not just sterilization but including the IUD and other temporary methods. Project staff regularly visited the clinics and reviewed the monthly service statistics to assess the method mix of the clinic.

\section{Impact Assessment}

Multiple sources of data were used to assess the impact of the interventions, including:

Service statistics: Monthly service statistics were collected on IUD insertions during the nine month intervention period. A comparison of service statistics before and after the intervention in the study area provided an estimate of the impact of the interventions on IUD use.

Sample Survey: In the experimental area, pre and post intervention community-level surveys of potential clients were conducted to assess the impact of the interventions on knowledge and perceptions of the IUD, particularly regarding myths about the method. All married women aged 35 and under and their husbands were considered potential clients for IUD and so eligible for inclusion (women above 35 years of age generally adopt sterilization). While the impact of the interventions in increasing the use of the IUD was largely assessed from service statistics, the findings from the sample surveys were used for assessing changes in knowledge about the IUD, reduction in the myths associated with IUD use, increase in intention to use the method for spacing and/or limiting child bearing, and an overall favorable environment for IUD use. The number of potential clients interviewed during baseline and end line surveys is given in Table 3; data were collected through Table 3: Sample Coverage of Baseline and Endline Surveys face-to-face interviews using structured questionnaires. Baseline and endline surveys were conducted by the Centre for Operations Research and Training (CORT), which was selected after competitive bidding. Interviews were conducted by trained investigators experienced in the informed consent process and interviewing techniques using a questionnaire developed by FRONTIERS. Three days of classroom training and one-half day of practical training were provided.

Provider Interviews: All female health providers (ANM, LHV, PHN) who insert and remove IUDs were interviewed, both at the beginning and the end of the study, to assess their knowledge, attitudes and counseling skills for the IUD. A total of 76 providers at baseline and 77 providers at end line were interviewed. Information on the quality of services and details of how counseling was being done with clients was also collected. 
Follow-up of IUD users: To assess the quality of counseling and services provided before, during and after insertion of the IUD, 10 IUD users from each PHC/ VMC area were interviewed. These IUD users were randomly selected from the registers of the HCPs from each study area. Evidence from other studies suggests that the largest number of IUD discontinuations occur in the first 6-8 weeks following insertion. A total of 83 and 205 IUD users were interviewed at baseline and at the endline survey respectively to assess the quality of IUD services in the study area.

Perception of Pharmacists about IUD: The study also made an attempt to find out the perceptions of pharmacists and chemist shop owners about the IUD and their willingness to participate in the awareness raising activities; a total of 50 pharmacists/ chemist shop owner were interviewed during the endline survey.

Qualitative Assessment: To complement the survey, a small amount of qualitative data was also collected. This included five FGDs of providers (3 rural areas and 2 urban areas) and 10 FGDs with women (6 rural and 4 urban areas).

\section{FINDINGS}

\section{Perceptions of the IUD}

The formative research showed a wide range of misconceptions among men and women (Box 1). Some of the more serious concerns shared by many were: the IUD causes cancer; it increases the weight of women; after insertion the IUD causes a lot of pain and walking becomes difficult; it moves out of uterus and travels inside body/heart; and it hurts men during intercourse (See Box1).

FGDs with providers also showed varying degrees of misconceptions. Most believed that:

"Newly married women should not be given the IUD as it causes infection and she may not able to bear child in future. We do not advise them to use the IUD."

Another myth shared by most ANM was: "The IUD is not good for women with many children. Their uterus becomes loose. IUD does not stay. It comes out."

\section{Box 1: Voices from the field}

- "Aankadi (IUD) is used by women to prevent pregnancy and it closes the tube; it can be opened when one wants child"

- "After using, women gain a lot of weight"

- "In the village woman has to do a lot of work, IUD causes pain and even walking becomes difficult"

- "When I used aankadi it came out with my menstruation. Other women also shared this experience”

- "One can't do heavy work with aankadi. Women say that by lifting heavy weight it comes out"

- "Aankadi travels from its position to different parts of the body and affects liver, kidney and sometimes heart also"

- "Aankadi causes damage to male organs during sex. The woman has chances of getting cancer also" 
For many providers, counseling on the IUD was time consuming and difficult:

"Few women are ready to use IUD. Even among educated families lot of counseling is required. Many times male members of the family are against the use of this method. It hurts the males during intercourse."

One of the providers in an urban area mentioned:

"Till three months after caesarean and forty days after normal delivery, IUD cannot be inserted as mouth of uterus remains open and chance of IUD falling out is high."

Program emphasis on female sterilization as a limiting factor in stimulating demand for the IUD was reported by many ANMs:

"We face pressure from our supervisors to achieve the sterilization target. Nobody asks us about the IUD performance."

Based on the findings of the formative research, a set of BCC materials were developed and a separate session during the training of workers was devoted to addressing these misconceptions. As mentioned, a set qualitative data was collected and the results were presented with findings of quantitative survey.

\section{Effects of the Intervention on Providers}

To assess the impact of the intervention, 76 and 77 HCPs were interviewed in baseline and endline surveys respectively. Sixty-two percent were from rural areas; the average age of HCPs was around 42 years and the average years spent in service was around 17 years. The background characteristics of HCPs are presented in appendix 1.

Knowledge of the IUD among HCPs: Correct and complete knowledge of the IUD has a direct bearing on the quality of counseling and provision of IUD services. Analysis of their knowledge before training and at the end of the study showed significant improvements after the intervention, the only exception being that the IUD does not interfere with couple's pleasure during sex (Table 4).

\begin{tabular}{|l|c|c|}
\hline \multicolumn{3}{|c|}{ Table 4: Change in Knowledge About IUD Among the HCPs } \\
\hline Percentage aware or knew that & Baseline & Endline \\
\hline It is a very effective family planning method & 48.7 & $71.4^{*}$ \\
\hline It protects from pregnancy up to 10 years & 78.9 & $96.1^{* *}$ \\
\hline How IUD works & 84.2 & 87.0 \\
\hline It should not be inserted in woman having an STI/ abnormal discharge & 40.8 & $67.5^{\star *}$ \\
\hline First follow-up should be done after 3 to 6 weeks of IUD insertion & 50 & $80.5^{\star *}$ \\
\hline IUD does not have hormonal side effects & 19.7 & 24.7 \\
\hline IUD does not interfere during sex & 23.7 & 13.0 \\
\hline Number of HCPs & 76 & 77 \\
\hline${ }^{*}$ p $<0.05,{ }^{* *}$ p $<0.01$ & \multicolumn{2}{|}{} \\
\hline
\end{tabular}

To create a composite index of IUD knowledge, answers were scored by assigning each correct response a score of ' 1 ' and wrong answers as ' 0 ', giving a range of scores from 0 to 39 . The scores achieved were then divided into quartiles: all those scoring in the first quartile $(<11)$ were categorized as having low knowledge; the second and third quartiles together (11-30) categorized 
as medium or average knowledge; and providers scoring in the fourth quartile ( $>30)$, were categorized as having good knowledge.

As Figure 1 shows, the majority (88 percent) of HCPs were found to have average knowledge at baseline, while approximately 12 percent had low levels of knowledge before the intervention. At the endline, almost all (97.4 percent) providers had average knowledge and very few (2.6 percent) had low level of knowledge. None of the providers could score a 'good' grade in knowledge even after the intervention, indicating the need for sustained brief on the job training.

\section{Figure 1: Level of IUD Knowledge among HCPs Before}

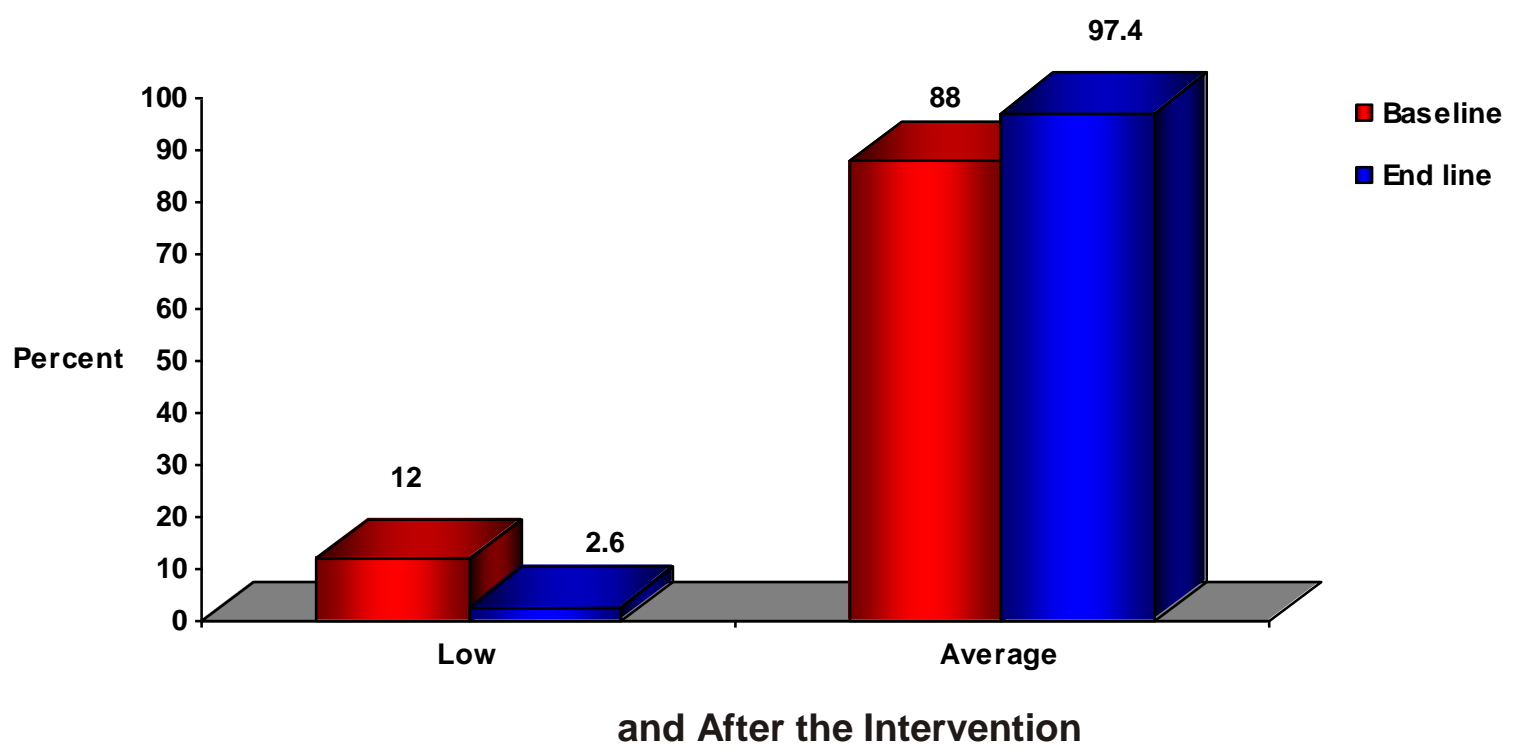

The individual indicators included in the assessment of providers' knowledge are described in appendix 2. One important improvement (79 percent to 96 percent) was knowing that the IUD is a long-acting method and could be retained up to 10 years after insertion.

Reflecting on the training they received, one female health worker reported:

"Although we knew many things about the IUD, we received detail in-depth information about the IUD in the training, as it addresses IUD insertion, how to motivate women and how to deal in case of complication. We got a lot of new information and our knowledge regarding the IUD has increased manifolds".

Counseling skills of HCPs: Through counseling, providers help clients to make informed contraceptive choices. Good counseling makes clients satisfied with their choice and facilitates continuation of method use. Table 5 lists the key indicators that were used for assessing the counseling skills of the providers. Most indicators (7 of 10) showed significant increases $(\mathrm{p}<0.05)$ from the baseline value. As with the knowledge levels, the counseling skills were also categorized into poor (score <3), average (score 3-7) and good (score >7). 
A significant improvement in the proportion of HCPs with average counseling skills was seen after the training (Figure 2). None of the HCPs, however, scored a 'good' grade in counseling even after the training. This again underlines the need for guidance in improving counseling skills. Due to the unavailability of job aids, the HCPs were handicapped in keeping their counseling focused and effective. At the time of the baseline survey, none of the HCPs had leaflets or handouts which they could give to clients for reading and gaining correct knowledge about the IUD. These limitations however, were addressed as part of the intervention by providing

Table 5: Selected Indicators to Assess Counseling Skills of HCP

\begin{tabular}{|c|c|c|}
\hline Percentage aware or knew that & Baseline & Endline \\
\hline \multicolumn{3}{|l|}{ Before IUD insertion } \\
\hline Mechanism of action & 19.7 & $45.5 * *$ \\
\hline Advantages & 85.5 & $96.1 *$ \\
\hline Adverse effects and complications & 44.7 & $62.3 *$ \\
\hline When IUD should be inserted & 40.8 & 53.2 \\
\hline Effectiveness & 65.8 & $48.1^{*}$ \\
\hline Procedure of insertion & 2.6 & 9.1 \\
\hline \multicolumn{3}{|l|}{ After IUD insertion } \\
\hline Potential immediate problems & 71.1 & $93.5^{* *}$ \\
\hline How to check IUD strings at home* & 11.8 & $29.9 * *$ \\
\hline Follow up schedule & 23.7 & 32.5 \\
\hline \multicolumn{3}{|l|}{ Counseling at follow up visit } \\
\hline Discussion on side effects* & 10.5 & $96.1^{*}$ \\
\hline Number of respondents & 76 & 77 \\
\hline
\end{tabular}

them with a flip chart as a counseling aid, besides adequate numbers of leaflets to share with clients.

Figure 2: Level of counseling skills of HCPs after Intervention

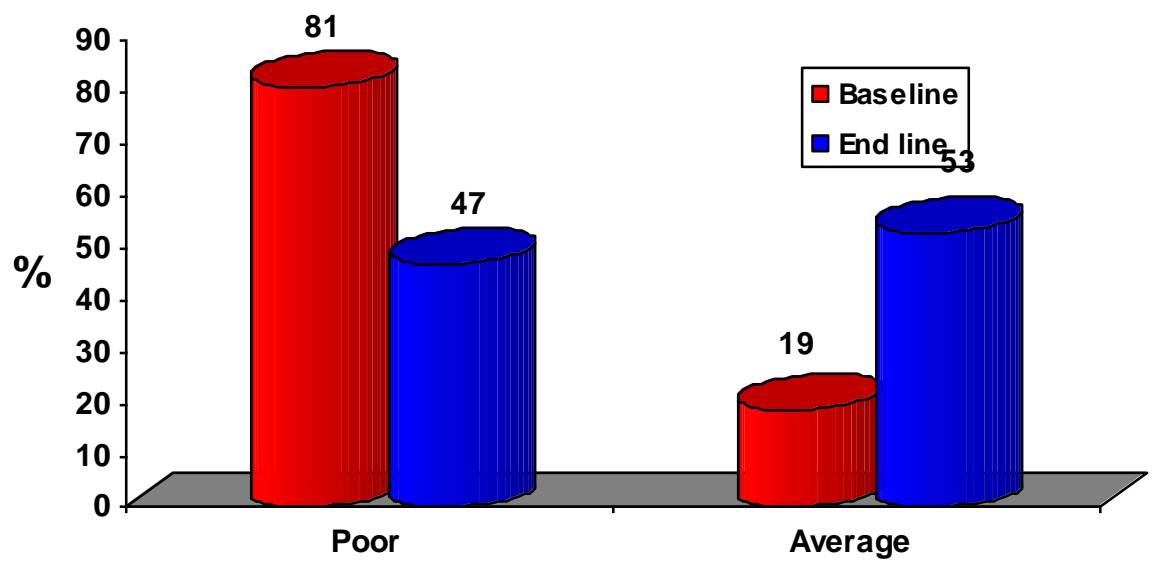

Technical skills of HCPs: To evaluate their technical skills for inserting and removing the IUD, all HCPs were asked to narrate the stepwise process of IUD insertion and removal according to the technical guidelines of the MOHFW; 22 and 14 steps were prepared for IUD insertion and removal, respectively. The details of each step with the improvements at endline survey are given in appendix 3 and 4 respectively. 
Out of these 22 steps for IUD insertion, six critical steps (washing of hands, using of disinfected/sterile gloves, loading of IUD by the no touch technique, measuring uterine length by uterine sound, inserting the IUD using the withdrawal technique

\begin{tabular}{|l|c|c|}
\hline $\begin{array}{c}\text { Table 6: Knowledge of HCPs about Selected Critical } \\
\text { Steps for IUD Insertion and Removal }\end{array}$ \\
\hline Percentage knew & Baseline & Endline \\
\hline Six critical steps for IUD insertion & 5.0 & $40.3^{\star \star}$ \\
\hline Five critical steps for IUD removal & 12.0 & $29.9^{* \star}$ \\
\hline Number of respondents & $\mathbf{7 6}$ & $\mathbf{7 7}$ \\
\hline${ }^{* \star} \mathrm{p}<0.01$ & & \\
\hline
\end{tabular}

and showing the cut end of IUD string to the clients) were identified (Table 6). The responses of HCPs were analyzed based on these six critical steps; their technical knowledge for IUD insertion was considered 'good' if the HCP mentioned all six critical steps. The proportion of HCPs with 'good' IUD insertion skills increased from 5 percent at the baseline to 40.3 percent at the endline ( $\mathrm{p}<0.01)$. Similarly for IUD removal, five critical steps (washing of hands, using of disinfected/sterile gloves, localizing cervix, looking for IUD thread and pulling it out and showing the removed IUD to the client) were identified. Technical knowledge for IUD removal was considered 'good' if the HCPs mentioned all the five critical steps. Similarly, the proportion of HCPs with 'good' IUD removal skills increased from 12 percent to 30 percent $(\mathrm{p}<0.05)$.

These findings indicate that the intervention was largely successful in strengthening technical skills of the providers after nine months of training and practice. The findings also indicate, however, that the technical skills of the majority of ANMs remained average but not sufficient to meet desired clinical standards. This suggests the need for additional sessions to strengthen their skills to the level required.

Attitude of HCPs towards the IUD: Attitudes of the providers towards any contraceptive method has a direct bearing on their counseling efforts and the quality of services. The study assessed the attitude of providers in terms of their personal bias, trend of IUD acceptance in the community, their perceptions about the IUD, and personal use of the IUD. To assess personal bias, the HCPs were asked whether they would recommend the IUD to a newly married couple (see appendix 5 for list of indicators). One third of HCPs said they would do so at the endline compared with 1.3 percent at baseline. The majority ( 61 percent) of providers believed that, because of increased awareness about the IUD, its use during the last one year had increased; however, 16 percent felt that use had actually decreased in their areas. Approximately one-third of providers believed sterilization was the preferred method, while the IUD was mentioned by only 18 percent of providers. Significant increases were found in HCPs' perceptions of the desirable features of the IUD, i.e., use as a long-term method ( $83 \%$ vs.41\%); one time insertion (51\% vs. $17 \%$ ); and suitable for most couples (33\% vs. $7 \%$ ). Very few HCPs believed that the IUD could be a good alternative to sterilization, and there was only a small increase in the proportion of HCPs holding this view (from 6\% to 13\%).

Overall many providers had a positive attitude towards the IUD and believed that it was a good and safe contraceptive method, as was reflected in 40 percent of the providers or their wives being IUD users at the endline, compared with 32 percent at baseline. Furthermore, almost all (99 percent) said that they would easily recommend it to their friends or relatives. 
The HCPs positive attitude towards the IUD also emerged during focus group discussion. One of the HCPs said that;

"It (IUD) is safe and the best method among all methods for women. She is tension free from taking oral pills regularly, which is a problem with this method, as one forgets to take it sometimes. It is difficult for men to use condom every time, it tears and its use also depends on the attitude of the partner."

One of the ANMs in a rural area mentioned that, "IUD is a very effective method of family planning. Earlier women used to accept operation after two children, as IUD can be used for ten years, it is as good a method as operation."

HCPs Experience with IEC materials: The IEC materials and the counseling aids that were developed for the project were evaluated as highly useful and effective. All HCPs had seen and read the IEC materials provided to them. A majority ( 92 percent) had used these materials to counsel the clients. About 90 percent of the HCPs reported that they 'always' use these materials and 80 percent had used this materials last week. Only 5 percent of HCPs reported that they had run out of stock. According to the HCPs, about 60 percent of the clients found the client leaflet informative, 80 percent found it useful and about 40 percent told that the materials helped them to understand more about the IUD. About 95 percent of HCP thought that their counseling performance had improved dramatically after receiving these IEC materials. About 65 percent reported that they were now confident and 50 percent felt that they were now good counselors.

One supervisor reported:

"The chart related to IUD insertion and removal is very useful for us. If we follow these steps then the chance of infection will become less, in case of any mistakes in IUD insertion we rectify it by seeing the chart"

One of the ANMs in an urban health center mentioned during an FGD that:

"'We use leaflets to explain about the IUD and by showing the pictures of the leaflet and the small booklet (counseling aid) we tell them about its benefits, disadvantages, its size and where it is kept in the human body. We found these materials very helpful."

Another supervisor from a rural area said that:

"The IEC materials which we have received, we can share with the clients. We give the material (client leaflets) to the educated mothers who come to us for advice or services. She can read and share it with her husband also. The leaflet gives information on how the IUD is inserted, and that it can be used for ten years.

Earlier we did not have anything to give to the clients except the IUD which we used to show them. Now these pictures are there which they can actually see. Pamphlets are there which they themselves can read and understand, as well as share it with others." 


\section{Effects of the Intervention on Clients}

A comparison of the characteristics of the two samples interviewed at baseline and endline showed that they were matched and that their background characteristics typically represent the general population of the study area. The mean age was 26.5 years and the majority (89\%) was Hindus. Selected household characteristics of women during baseline and endline survey are given in appendix 6 .

Knowledge of the IUD: The intervention helped in making clients, particularly men, better aware of the IUD. The endline survey shows that 10 percent of respondents $(6 \%$ women, $18 \%$ husbands) were still not aware of the IUD, but this was significantly less than the 23 percent at baseline (14\% women and $41 \%$ husbands).

The educational campaign helped increasing knowledge about certain key aspects of the IUD (see Table 7). The largest gains were observed on the timing when the IUD could be inserted, but all other items also increased significantly, but overall the proportion of such respondents with this knowledge remained low. Greater diffusion of this information in the population will require more time and a sustained effort by the program.

For women, key sources of information about the IUD remained

\begin{tabular}{|c|c|c|}
\hline Percentage aware or knew that & Baseline & Endline \\
\hline $\begin{array}{l}\text { IUD protects from pregnancy up to } \\
10 \text { years }\end{array}$ & 4.2 & $29.2^{* *}$ \\
\hline IUD is inserted in the uterus & 23.2 & $37.5^{\star *}$ \\
\hline How IUD works & 8.0 & $15.3^{* *}$ \\
\hline $\begin{array}{l}\text { IUD can be inserted immediately } \\
\text { after menstruation }\end{array}$ & 53.2 & $60.7^{* *}$ \\
\hline $\begin{array}{l}\text { It can be inserted anytime after } 6 \\
\text { weeks of delivery }\end{array}$ & 24.7 & $63.7^{* *}$ \\
\hline Number of respondents & 894 & 880 \\
\hline
\end{tabular}
similar at the endline survey, with almost half of women mentioning friends or relatives, and one quarter each mentioning doctors and family members. However, fifty percent of women reported the ANM to be the main source of information at the endline, compared with 28 percent at baseline, and eight percent reported the AWW as the main source of information compared with none at baseline. This indicates that both ANMs and AWWs have tried to inform their clients about the IUD.

An aggregate score for clients' knowledge of the IUD was created by scoring 1 or 0 for their answers to the questions, giving a range of scores from 0 to 29. The scores achieved were categorized into three levels of knowledge: low (<7), average (7-21) and high (>21). The individual indicators and the scores are described in appendix 7. Significant increases are seen in 17 out of the 29 indicators.

Table 8 shows that the proportion of women with an average level of knowledge increased significantly. However, a substantial proportion of women, both in rural and urban areas, remained with poor knowledge and not a single woman could be categorized as having good knowledge. Similar findings were found for husbands' knowledge, although two-third of males 
remained with poor knowledge, again underlining the need for a sustained IEC campaign for a longer period to diffuse correct information about the IUD.

\begin{tabular}{|c|c|c|c|c|c|c|}
\hline \multicolumn{7}{|c|}{ Table 8: Change in Level of IUD Knowledge Among Women } \\
\hline & \multicolumn{2}{|c|}{ Urban \% } & \multicolumn{2}{|c|}{ Rural \% } & \multicolumn{2}{|c|}{ Total \% } \\
\hline Level of knowledge & Baseline & Endline & Baseline & Endline & Baseline & Endline \\
\hline \multicolumn{7}{|c|}{ Women } \\
\hline Average & 24.7 & $55.6^{\star \star}$ & 13.3 & $44.4^{\star *}$ & 19 & $53^{* *}$ \\
\hline Poor & 75.3 & $46.1^{\text {** }}$ & 86.7 & $53.9^{* *}$ & 81 & $47^{* \star}$ \\
\hline $\mathbf{N}$ & 449 & 450 & 445 & 430 & 894 & 880 \\
\hline \multicolumn{7}{|c|}{ Husbands } \\
\hline Average & 4.9 & $23.9^{\star \star}$ & 3.8 & $22.2^{\star \star}$ & 4.4 & $23.3^{\star \star}$ \\
\hline Poor & 95.1 & $76.1^{\star \star}$ & 96.2 & $77.8^{\star \star}$ & 95.6 & $76.8^{\star \star}$ \\
\hline $\mathbf{N}$ & 223 & 235 & 212 & 217 & 435 & 452 \\
\hline
\end{tabular}

Myths about to the IUD: Various myths related to IUD use prevail throughout India, and this study area was no exception. Comparison of the baseline and endline data (see Table 9) shows that, in general, the educational effort has succeeded in reducing various myths about the IUD. For example only 22 percent at the endline compared with 44 percent at baseline believed that use of the IUD causes weight gain. A similar decrease was observed in the proportion of women believing that the IUD causes discomfort during sexual intercourse or that it causes cancers. However, many myths still prevail and a prolonged IEC campaign is required to address these myths and misconceptions.

Qualitative data collected during the endline survey also

\begin{tabular}{|l|c|c|}
\hline \multicolumn{3}{|l|}{ Table 9: Myths about the IUD among women } \\
\hline Percentage aware or knew that & Baseline & Endline \\
\hline IUD causes weight gain & 44.2 & $21.6^{* *}$ \\
\hline IUD causes frequent and heavy bleeding & 40.5 & $49.5^{\star *}$ \\
\hline IUD travels to different body parts & 31.6 & $27.3^{*}$ \\
\hline $\begin{array}{l}\text { IUD causes discomfort during sexual } \\
\text { intercourse }\end{array}$ & 18.0 & $9.0^{* *}$ \\
\hline IUD causes cancer & 6.5 & $1.8^{\star *}$ \\
\hline No of Respondents & 894 & 880 \\
\hline${ }^{*} P<0.05,{ }^{* *} \mathrm{P}<0.01$ & & \\
\hline
\end{tabular}
substantiates these findings:

One woman in a rural area said during a FGDs that, "Aankdi (IUD) gets dislocated, displaced, pinches or it also comes out. But this happens once in hundred cases. Since four years I am using IUD but nothing like this happened."

Another woman in an urban area commented,

"Some women say that it increases weight and some say that the body becomes weak after Aankdi (IUD) use. But actually nothing like this happens in reality."

\section{Reported Quality of IUD services by Users}

Quality of counseling and services were assessed through following up IUD users. At baseline, 83 women (40 urban and 43 rural) were randomly selected at 6-8 weeks after insertion from each clinic register and interviewed. During the intervention period, another sample of 205 IUD users was followed. The background characteristics of women who use the IUD are presented in 
appendix 8. In general, the mean age was 25-26 years, most women (90\%) were literate, onethird had 11 or more years of schooling, and most belonged to the higher caste group (80\%). After the intervention, IUD use among Muslims and other Hindu caste groups improved, suggesting that the project has helped in increasing IUD use in other castes also.

Selected components of the quality of IUD services, such as pre-insertion counseling, maintenance of privacy during the counseling and procedure, screening of clients before insertion of IUD, infection prevention practices and followup advice given to the clients before leaving the health facility

\begin{tabular}{|l|c|c|c|}
\hline \multicolumn{4}{|c|}{$\begin{array}{c}\text { Table 10: Reported Quality of Care by IUD acceptors } \\
\text { (Mean Score } \pm \text { SD) }\end{array}$} \\
\hline & $\begin{array}{c}\text { Baseline } \\
(\mathbf{N}=\mathbf{8 3})\end{array}$ & $\begin{array}{c}\text { Endline } \\
(\mathbf{N}=\mathbf{2 0 5})\end{array}$ & $\begin{array}{c}\text { Maximum } \\
\text { score }\end{array}$ \\
\hline Pre-insertion counseling & $6.6( \pm 2.3)$ & $8.5( \pm 2.3)^{*}$ & 11 \\
\hline Privacy maintenance & $2.7( \pm 0.5)$ & $2.9( \pm 0.4)^{*}$ & 3 \\
\hline Screening of clients & $4.2( \pm 1.9)$ & $6.1( \pm 2.1)^{*}$ & 10 \\
\hline Infection prevention & $3.8( \pm 0.6)$ & $3.9( \pm 0.2)$ & 4 \\
\hline Follow up advice & $4.3( \pm 1.2)$ & $5.2( \pm 0.9)^{*}$ & 6 \\
\hline${ }^{*} \mathrm{p}<0.05$ & \multicolumn{4}{|l}{} \\
\hline
\end{tabular}
were assessed by asking clients their experiences. As can be seen in Table 10, significant improvements were observed in each component of IUD care, except maintenance of privacy during counseling and the procedure, but this was high even before intervention and hence there was not much scope for improvement.

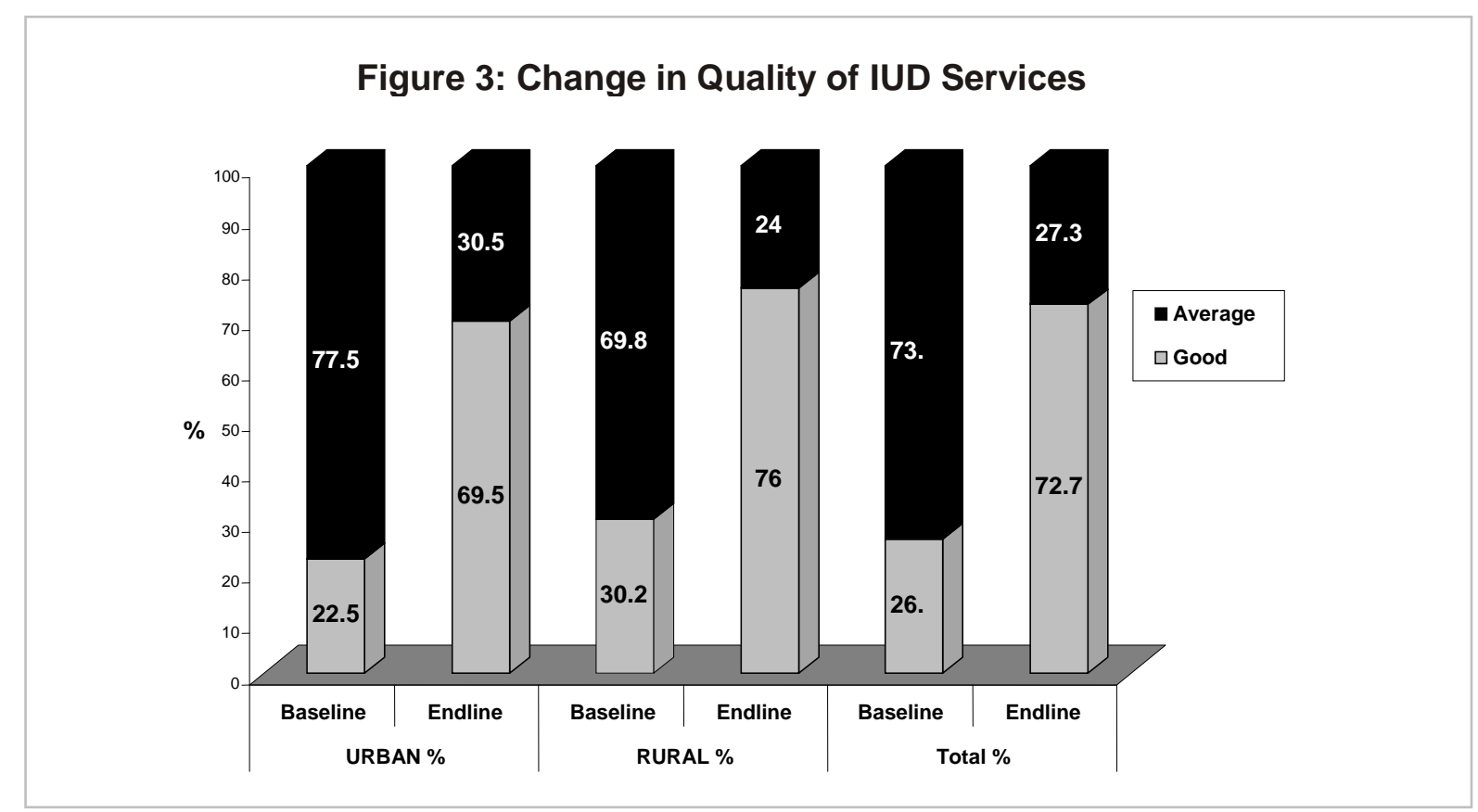

To create an aggregate index of quality, all questions were assigned a score ' 1 ' or ' 0 ', depending on whether or not the client reported that the provider carried out the activity. The maximum and minimum scores ranged between 0 and 34 , and the scores were categorized into good $(\geq 25$ scores), average (9-24 scores) and poor ( $\leq 8$ scores). After nine months of intervention, the proportion of women who received a good quality service increased significantly from 27 percent to 74 percent. This improvement was noticed both in urban and rural areas (Figure 3). The indicators included in assessing the quality of IUD services are given in appendix 10. Out of the 34 indicators, 19 showed significant improvement. 
Eighty two percent IUD acceptors had received the client leaflets from the providers and 72 percent of them had seen the IUD poster displayed at the health centers. Ninety three percent of them told that the content of the leaflet was easy to read and understand.

The qualitative survey also reiterated this fact. One IUD acceptor in the community said that, "We have seen the leaflet and poster. It is green in color. The text on it is simple, easy to read and understand. It can be remembered also. On reading the leaflet we know that it helps in spacing between the children."

\section{Validity of the Service Statistics during the Intervention}

As one of the key outcome indicators was the number of IUDs inserted, and this was obtained from routine service statistics, an attempt was made to assess the validity of the service statistics. The follow-up survey at the baseline revealed an overall 45 percent over-reporting of IUD use; out of 150 IUD cases followed up, 67 cases were false. Wide variation in rural and urban area was observed; in rural areas false reporting was as high as 52 percent ( 52 false case out of 95 surveyed cases) as compared to 28 percent in urban areas (15 false cases out of 55 followed up).

These figures were discussed with the HCPs, the MOIC and the district level managers. While the finding was upsetting, it was credible. Over-reporting is not uncommon and has been reported in other states also. For example, a recent follow-up visit of IUD acceptors in eight districts of Uttar Pradesh revealed 70 percent inflation in the reported figures of IUD use (Mishra 2004). The project staff and the MOIC discussed this with the HCPs and encouraged them not to inflate the figures. They were also told that their performance would be measured in terms of good quality work, satisfaction of the clients and continuation of IUD use, and not by the number of insertions they report. To monitor the accuracy of data and quality of IUD insertion, samples of both rural and urban IUD users were followed up at regular intervals by selecting a sample from the service register randomly. The results of the follow-up during the post-intervention period were encouraging and misreporting of IUD cases was much lower at just 1.9 percent (4 cases out of 205 followed up). This decline was due to continuous monitoring during monthly meetings by the medical officers in the study areas and emphasis was placed on the quality of services rather than the volume.

\section{Trends in IUD Insertions}

To assess the impact of the interventions on IUD use, service statistics for the year of the intervention (2007) and the matching months of the previous year (2006) were collected for all study clinics, and the average number of users and the trend in use were compared; the 2006 data were adjusted for over-reporting. Figure 4 shows that, after the intervention, IUD use increased significantly in both rural and urban areas. In urban areas, at endline, use of the IUD was averaging around 247 IUDs per month as compared to 212 in 2006 (Figure 4). 
Figure 4: IUD Insertion Rate in Urban Areas in 2006-07

No of IUD Insertions

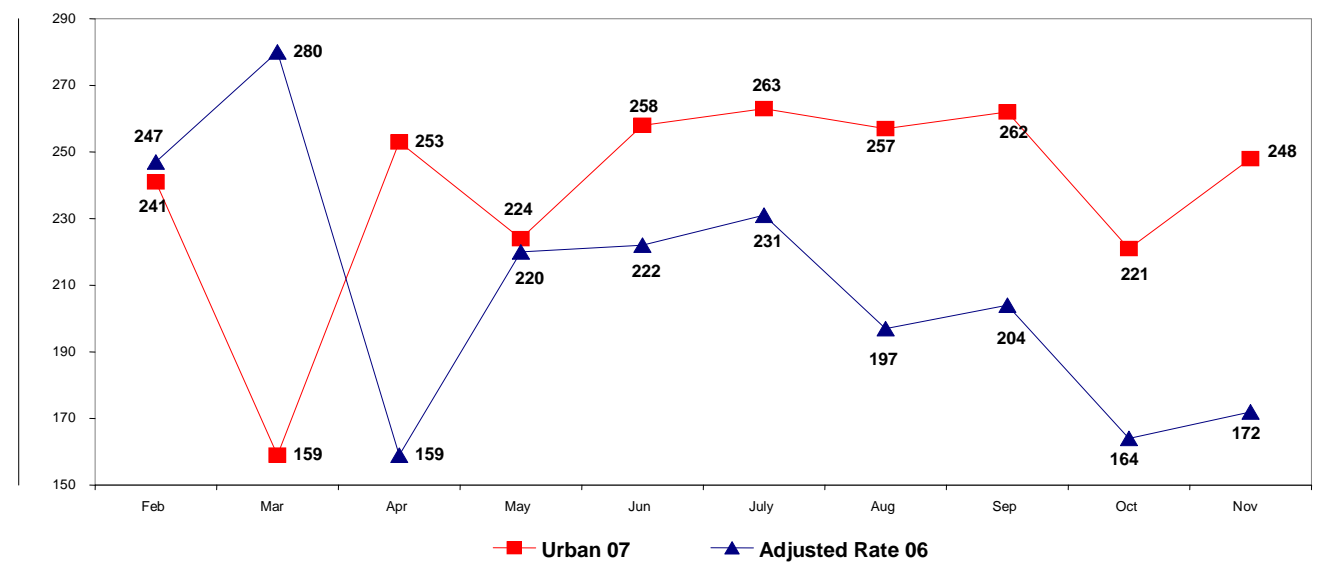

The same pattern was seen in the rural areas, with the intervention demonstrating positive results and slowly following an increasing trend. During 2007, the average number using the IUD was around 106 per month in the study area as compared to 46 during 2006 (Figure 5). As public health interventions take time to show results, these early improvements in a short duration are encouraging and suggest that the model developed and tested is effective in increasing use of the IUD. We believe that with improvements in quality of IUD services, coupled with demand generation activities, the increasing trend of IUD will continue over time.

Figure 5: IUD Insertion Rate in Rural Areas in 2006-07

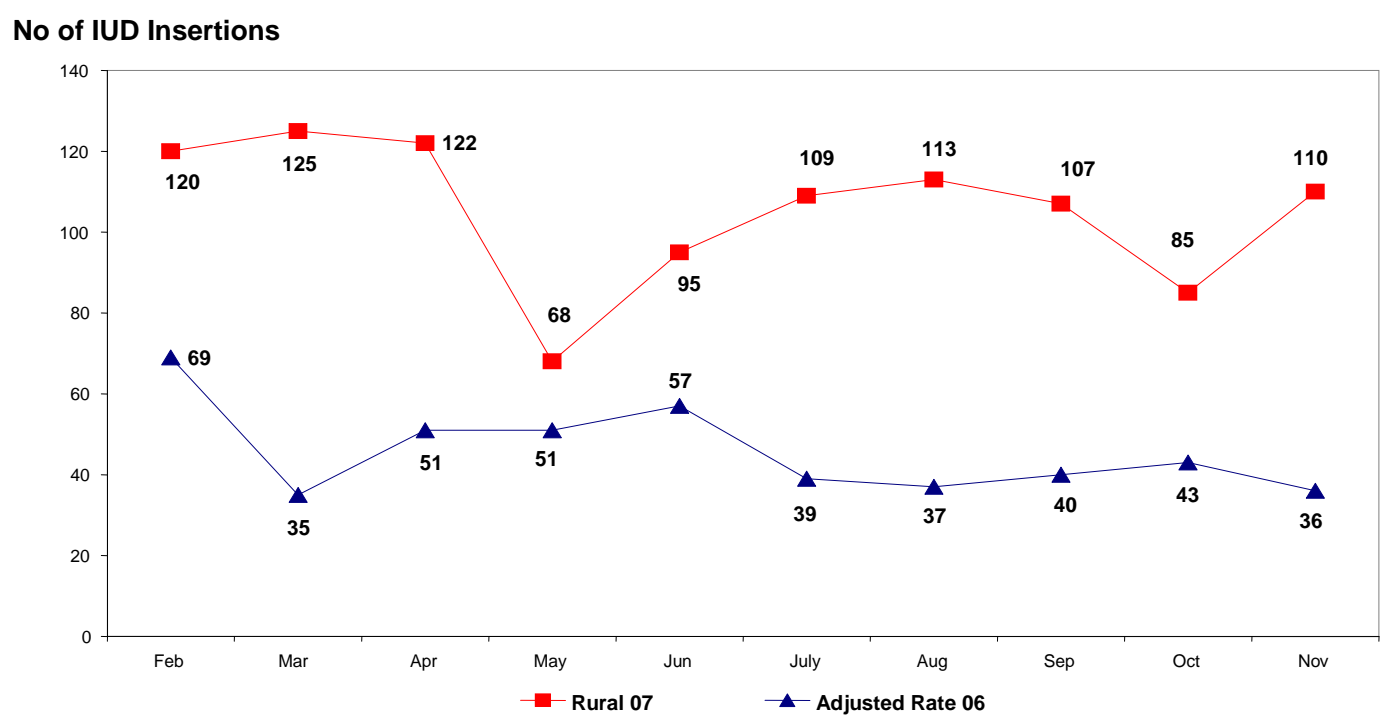




\section{Perception of Pharmacists about the IUD}

The study also investigated the perceptions of pharmacists/ chemist shop owners about the IUD and their willingness to participate in the awareness raising activity. A total of 50 pharmacists/ chemist shop owners were interviewed during the endline survey. Fifty-six percent of them reported that the IUD is inserted in the uterus, 43 percent reported that it is a very effective family planning method, and only 6 percent knew that the IUD can provide protection for up to 10 years. Approximately one-fourth of pharmacists sell the IUD in their shops, the brand being the Multiload IUD in all cases. Most expressed their interest in displaying posters (88 percent) and distributing IUD client leaflets (90 percent) in community. Involving pharmacists and chemist shop owners may be an innovative strategy to promote awareness regarding the IUD in the community.

\section{Economic Analysis of the Intervention Model}

Table 11 provides information on the costs of various components of the intervention model as implemented in the Vadodara district. The costs of intervention had four main components. Training, trainers fees, development and printing of the IEC materials and the cost for supervisory visits by FRONTIERS staff. These visits were primarily to PHC s and urban clinics, for reviewing performance of workers. Costs of visits by FRONTIERS staff for training interviewers and/or observing data collection have been not included as they were allocated as research costs. Cost of the IUD and dispensable items have not been calculated as those are freely provided by the Government. Similarly, the salary of the ANMs and doctors who attended the training has not been included in the calculation. Thus the costs that have been included are additional expenses that had to be spent for implementation.

\begin{tabular}{|c|c|c|}
\hline \multicolumn{3}{|c|}{ Table 11: Costs Incurred during Implementation of Intervention } \\
\hline Cost items & $\begin{array}{l}\text { Amount } \\
\text { (in INR) }\end{array}$ & $\begin{array}{c}\text { Amount } \\
\text { (in Dollars) }\end{array}$ \\
\hline \multicolumn{3}{|l|}{ A. Training } \\
\hline Off-site training of paramedical workers & 20,480 & 512 \\
\hline Off-site training of doctors & 5,110 & 128 \\
\hline Off-site training of private practitioners & 5,110 & 128 \\
\hline Off-site refresher training of paramedical workers & 1,000 & 25 \\
\hline Travel cost of council staff during training (2 visits) & 40,000 & 1,000 \\
\hline \multicolumn{3}{|l|}{ B. Trainer Fees } \\
\hline Professional fees for external expert (13 days) & 13,000 & 325 \\
\hline Professional fee of FRONTIERS staff (8 days) & 19,386 & 485 \\
\hline \multicolumn{3}{|l|}{ C. Development of IEC materials } \\
\hline Cost of development and printing IEC materials* & 47,752 & 1,194 \\
\hline \multicolumn{3}{|l|}{ D. Cost of Supervisory Visits } \\
\hline Travel cost for supervisory visit (5 visits) & 100,000 & 2,500 \\
\hline Total cost & 251,838 & 6,296 \\
\hline
\end{tabular}


When scaling up the program, cost components for involvement of FRONTIERS staff would not need to be included and training and supervision by non-FRONTIERS experts would be much lower. Adjusting for these costs, the total cost of the intervention would be around Rs 120,452. Routine service statistics showed that there were 886 new IUD users due to the intervention, giving a cost per new IUD user of Rs 135 (\$3.37) during scale up. As the study was implemented in 41 health centers, Rs 2,938 (\$73.5) would be the estimated unit cost to introduce the IUD services in an additional center.

\section{DISSEMINATION AND UTILIZATION}

Monitoring and process documentation were undertaken throughout the study. Three Research Updates and one Operations Research Summary, describing the baseline findings, implementation process and important lessons learned, were produced and widely disseminated. The findings were shared on a regular basis with the district and state health officials. The findings from the mid-term evaluation were presented at the "Symposium to Develop a Comprehensive Strategy for IUD Repositioning" in Lucknow in 2007, organized by MOHFW in collaboration with government of Uttar Pradesh, United States Agency for International Development (USAID), Family Health International (FHI), the Population Council, Constella Futures and the State Innovations in Family Planning Services Project Agency (SIFPSA). The results of the study were also presented at a FRONTIERS dissemination meeting, entitled 'Lessons Learned and Future Challenges in Reproductive Health Program' in New Delhi and at one day dissemination meetings each in Uttarakhand and Gujarat.

The IEC materials and counseling aids developed for the study were found to be effective and were appreciated by the state government which is considering printing them for the entire state. A

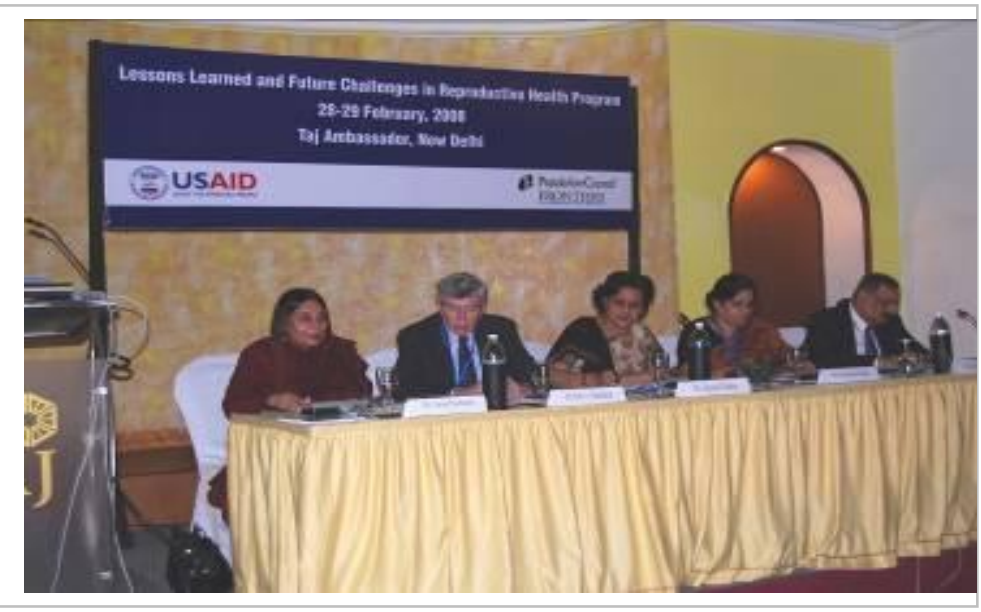
revised version of these IEC materials and the counseling aids have also been accepted by the IEC Division of the MOHFW, Government of India, and is being printed in different local languages for distribution among potential clients all over the country. 


\section{CONCLUSION AND LESSONS LEARNED}

- The model developed and tested both in urban and rural areas to reposition the IUD in the public sector program showed positive results in increasing use of the IUD and corrects knowledge about IUD. It has the potential to be scale-up in a phased manner. During the first phase it should be scaled up in at least two districts to assess the challenges.

- The interventions introduced are low-cost and could be easily integrated into the existing FP program. The study shows that the training helped in improving both technical and counseling skills of the workers and effects were reflected in significant improvements in the quality of the services provided by the workers. However, the results also revealed that one time training in developing counseling and technical skills is insufficient and they need 2-3 short orientation courses at regular interval such as 4 months. This training could be easily organized at the PHC using Medical College faculties and other communication experts for strengthening counseling skills. Further improvement could also be achieved by providing continuous supportive supervision and a positive programmatic environment where the provision of good quality services and services for the IUD are valued.

- Strengthening the IEC campaign, removing myths and disseminating correct and detailed information about the IUD is both critical and a challenge. In the absence of a planned IEC campaign on various family planning methods, particularly the IUD, it is not surprising that most women do not have correct information about the IUD. The situation among men is far worse. The study shows that even a limited effort was instrumental in increasing knowledge of the IUD, both among women and men. The results also show that the diffusion of knowledge was slow and that it would take time before the messages and information about the IUD reaches all potential stakeholders. The study revealed that besides providing posters and leaflets to HCPs or at health facilities, posters pasted at anganwadi centers and keeping IUD leaflets there helps in reaching young and potential clients for postpartum contraception. Clearly this demands a sustained and planned IEC effort.

- Educating clients with the help of counseling aids is more effective and helps in increasing acceptance of the method. At the start of the study, none of the providers had any educational materials with them to provide to the clients or counseling aids to use during counseling. The study shows that when counseling aids are provided to the HCPs they were highly appreciated and most of the providers use it regularly during counseling. The provision of counseling aids to providers should be an important part of the educational campaign.

- The IEC materials and counseling aids developed were effective and appreciated by the state government, which is considering printing them for the entire state. A revised version of these IEC materials has been accepted by the IEC Division of the MOHFW, Government of India, and is expected to be produced for the entire country. This is a testimony that the IEC materials developed under the project are of high quality and could be used in other parts of the country. 


\section{REFERENCES}

Gandotra, M. M. and N.P. Das. 1996. "Factors influencing choice of contraceptive and the reasons for its discontinuation," in Spacing as An Alternative Strategy: India's Family Welfare Programme, edited by M.E. Khan and G. Cernada. New Delhi. B.R. Publishing Corporation, pp. 95- 114.

International Institute for Population Sciences (IIPS) and Macro International. 2007. National Family Health Survey (NFHS-3), 2005-06: India: Volume I. Mumbai: IIPS.

Kar, Sitanshu Sekhar, M.E. Khan. "Operations Research in IUD-An Experience from Gujarat" Presentation made at the Symposium to Develop a Comprehensive Strategy for IUD Repositioning 2007. Organized by Ministry of Health and Family Welfare in collaboration with Government of UP, USAID, FHI, Population Council, Constella Futures, SIFPSA. 3 - 4th October 2007. Lucknow, India.

Khan, M.E., Bella C. Patel and R.B. Gupta. 1999. "The quality of family planning services in Uttar Pradesh from the perspective of service providers". In Improving Quality of Care in India's Family Welfare Programme edited by Michael A. Koenig and M.E. Khan. Population Council. New Delhi. pp. 238-269.

Khan, M.E., Sitanshu Sekhar Kar, Vikas Kishor Desai, Pratibha Patel and B P Itare. 2007. 'The model works! Interim findings from an OR project on repositioning of IUD in Gujarat'. Research Update No. 12, December 2007. New Delhi: Population Council/FRONTIERS.

Khan, M.E., Sitanshu Sekhar Kar, Vikas Kishor Desai and Pratibha Patel. 2007. 'The model works! Repositioning of IUD in public health program in India'. Research Update No. 12, December 2007. New Delhi: Population Council/FRONTIERS.

Mishra, Vinod K., Robert D. Retherford, P.S. Nair and Griffith Feeney. 1999. "Reasons for discontinuing and not intending to use contraception in India." National Family Health Survey Subject Report Number 13. International Institute for Population Sciences, Mumbai, India.

Mishra, Pradeep. 2004. 'A study on verification and follow up of IUD acceptors in rural areas of Uttar Pradesh'. Survey Report No. 83, December 2004. Population Research Center, Department of Economics, University of Lucknow.

Prochaska, J., O., C.C. DiClemente, J.C. Norcross.1992. "In Search of How People Change: Applications to Addictive Behaviors." American Psychologist 47 (9): 1102-1112.

Santhya, KG. 2003. "Changing family planning scenario in India: An overview of recent evidence". Regional Working Paper No. 17. Population Council, New Delhi. 


\section{APPENDICES}

\section{Appendix 1: Profile of Health Care Providers}

\begin{tabular}{|c|c|c|}
\hline \multicolumn{3}{|c|}{ Background Characteristics of the Providers of IUD, Vadodara } \\
\hline Particulars & $\begin{array}{c}\text { Baseline } \\
(\%)\end{array}$ & $\begin{array}{c}\text { Endline } \\
(\%)\end{array}$ \\
\hline $\begin{array}{l}\text { Professional Degree } \\
\text { MBBS or higher } \\
\text { Public Health Nurse } \\
\text { ANM/MPW } \\
\text { Female Health Worker }\end{array}$ & $\begin{array}{c}11.8 \\
2.6 \\
25 \\
44.7\end{array}$ & $\begin{array}{l}10.4 \\
2.6 \\
32.5 \\
44.2\end{array}$ \\
\hline $\begin{array}{l}\text { Age (in years) } \\
\leq 34 \\
35-39 \\
40-44 \\
45+ \\
\text { Mean age (in years) }\end{array}$ & $\begin{array}{l}17.1 \\
22.4 \\
18.4 \\
42.1 \\
41.9\end{array}$ & $\begin{array}{l}14.3 \\
23.4 \\
22.1 \\
40.3 \\
41.7\end{array}$ \\
\hline $\begin{array}{l}\text { No. of years of working experience } \\
\leq 10 \\
11-15 \\
16-20 \\
21+ \\
\text { Mean (in years) }\end{array}$ & $\begin{array}{r}18.4 \\
17.1 \\
34.2 \\
30.3 \\
17.1 \\
\end{array}$ & $\begin{array}{l}28.6 \\
11.7 \\
36.4 \\
23.4 \\
15.0\end{array}$ \\
\hline $\begin{array}{l}\text { Duration of years working in facility (in yrs) } \\
\leq 3 \\
4-5 \\
6-9 \\
10+ \\
\text { Mean (in years) }\end{array}$ & $\begin{array}{l}28.9 \\
19.7 \\
21.1 \\
30.3 \\
7.7\end{array}$ & $\begin{array}{l}13.2 \\
26.3 \\
15.8 \\
44.2 \\
9.6\end{array}$ \\
\hline $\begin{array}{l}\text { Place of residence } \\
\text { Within the campus, in quarters } \\
\text { Outside the campus, in same village/town } \\
\text { In another village/town close by } \\
\text { District headquarter town }\end{array}$ & $\begin{array}{c}10.5 \\
61.8 \\
23.8 \\
3.9\end{array}$ & $\begin{array}{l}6.5 \\
32.5 \\
26.0 \\
35.1\end{array}$ \\
\hline Total no. of providers & 76 & 77 \\
\hline
\end{tabular}




\section{Appendix 2: Parameters Considered to Assess Knowledge of HCPs on IUD}

\begin{tabular}{|c|c|c|}
\hline Parameters Considered to Assess Knowledge of HCPs & $\begin{array}{c}\text { Baseline } \\
(\%)\end{array}$ & Endline \%) \\
\hline 1. IUD is a very effective family planning method & 48.7 & $71.4 * *$ \\
\hline 2. IUD prevents sperm from fertilizing the ovum & 84.2 & 87.0 \\
\hline 3. IUD is a long lasting method (10 year protection) & 78.9 & $96.1 * * *$ \\
\hline 4. No daily up-keep is required in case of IUD users & 46.1 & $79.2 * * *$ \\
\hline 5. IUD doesn't interfere with sex & 23.7 & 13.0 \\
\hline 6. IUD has no hormonal side effects & 19.7 & 24.7 \\
\hline 7. Immediately reversible & 46.1 & $62.3^{*}$ \\
\hline 8. There is no interaction with any medicine & 9.2 & 16.9 \\
\hline 9. $\quad$ IUD does not affect breast milk & 10.5 & 11.7 \\
\hline 10. One time insertion & 42.1 & $71.4 * * *$ \\
\hline 11. Failure rate of IUD is $<1$ percent & 18.1 & 22.1 \\
\hline 12. Requires skilled provider to insert/ remove device & 47.4 & $72.7 * * *$ \\
\hline 13. Requires internal (pelvic examination) during IUD insertion & 17.1 & 13.0 \\
\hline 14. Does not protect against STI/HIV/AIDS & 39.5 & 49.4 \\
\hline 15. IUD may cause Heavier menstrual period & 76.3 & 75.3 \\
\hline 16. IUD can lead to cramping pain in abdomen for 2-3 days & 56.6 & $75.3 * *$ \\
\hline 17. IUD can be used by lactating mothers & 23.7 & 23.4 \\
\hline 18. IUD can be used by nulliparous women & 9.2 & $26.0 * *$ \\
\hline \multicolumn{3}{|l|}{ 19. IUD should not be inserted in women with } \\
\hline - Suspicion of pregnancy & 71.1 & 77.9 \\
\hline - Excessive menstrual bleeding/irregular bleeding & 65.8 & 74.0 \\
\hline - Cancer of reproductive tract & 14.5 & 23.4 \\
\hline - Severe anaemia & 31.6 & 19.5 \\
\hline - Previous history of ectopic pregnancy & 18.4 & 20.8 \\
\hline - Genitor-urinary tuberculosis & 19.7 & $49.4 * * *$ \\
\hline - History of septic abortion/puerperal sepsis in last three months & 13.2 & 6.5 \\
\hline \multicolumn{3}{|l|}{ 20. IUD can be inserted in a women in } \\
\hline - Any time during or immediately after menstrual cycle & 58.4 & $84.4 * * *$ \\
\hline - More than 6 weeks after child birth & 73.7 & 82.4 \\
\hline \multicolumn{3}{|l|}{ 21. IUD should not be inserted in } \\
\hline - Pregnancy & 73.7 & $89.6 * *$ \\
\hline - History of STI/PID in last 3 months & 47.4 & 41.6 \\
\hline - History of any abnormal vaginal discharge & 40.8 & $67.5^{* * *}$ \\
\hline - History of penile discharge in partner & 7.9 & 10.4 \\
\hline 22. IUD strings should be checked weekly during first month after insertion & 34.2 & 42.5 \\
\hline 23. First follow up visits should be done 3 to 6 weeks after IUD insertion & 50.0 & $80.5 * * *$ \\
\hline \multicolumn{3}{|l|}{ 24. IUD acceptors should see a HCP in case of } \\
\hline - $\quad$ Missed menstrual period & 65.8 & 62.3 \\
\hline - Irregular bleeding/ severe bleeding & 82.9 & 83.1 \\
\hline - Fever with an unusual vaginal discharge & 27.6 & 41.6 \\
\hline - Thread of IUD appears shorter/ longer or missing & 28.9 & $53.2 * *$ \\
\hline - Severe pain in the lower abdomen & 67.1 & 63.6 \\
\hline - She and her partner are not happy with IUD use & 2.6 & 7.3 \\
\hline Number of Health Care Providers & 76 & 77 \\
\hline
\end{tabular}




\section{Appendix 3: Selected Parameters considered to assess the Knowledge on IUD Insertion of HCPs}

\begin{tabular}{|c|c|c|}
\hline \multicolumn{3}{|c|}{ Selected parameters considered to assess the knowledge on IUD insertion of HCPs } \\
\hline & Baseline (\%) & Endline (\%) \\
\hline 1. Counsel the client & 9.2 & $54.7 * * *$ \\
\hline 2. Prepare the client & 47.3 & $90.7 * * *$ \\
\hline 3. Gather all the equipments necessary for insertion & 51.3 & 65.3 \\
\hline 4. Wash your hands with soap and water ${ }^{\#}$ & 52.6 & $86.7 * * *$ \\
\hline 5. Palpate abdomen & 2.6 & $32 * * *$ \\
\hline 6. Put on clean/highly disinfected gloves ${ }^{\#}$ & 64.4 & $82.7 * *$ \\
\hline 7. Clean clients external genitalia & 69.7 & 74.7 \\
\hline 8. Double check that instruments are ready & 1.3 & 9.3 \\
\hline 9. Insert sterile speculum & 64.4 & 57.3 \\
\hline 10. Inspect genitalia and urethral opening & 57.8 & $21.3 * * *$ \\
\hline 11. If facility for PAP smear is available, perform it & 0.0 & 1.3 \\
\hline 12. Perform bimanual palpation & 0.0 & 1.3 \\
\hline 13. Load IUD by no touch technique ${ }^{\#}$ & 15.8 & $68.0 * * *$ \\
\hline 14. Insert speculum again & 11.8 & $25.3 *$ \\
\hline 15. Put volsellum/ sponge holding forcep & 11.8 & $37.3 * *$ \\
\hline 16. Measure uterine length by uterine sound ${ }^{\#}$ & 84.7 & 84.0 \\
\hline 17. Insert IUD by withdrawal technique ${ }^{\#}$ & 80.2 & 81.3 \\
\hline 18. Cut the thread and show it to the client ${ }^{\#}$ & 80.2 & 88.0 \\
\hline $\begin{array}{l}\text { 19. Remove volsellum/ sponge holding forcep and } \\
\text { speculum }\end{array}$ & 43.4 & 46.7 \\
\hline 20. Wash your hands & 38.1 & $22.7 *$ \\
\hline 21. Complete client record & 28.9 & $66.7 * *$ \\
\hline 22. Counsel the client on follow-up procedure & 63.1 & 66.7 \\
\hline Number of HCPs & 76 & 77 \\
\hline
\end{tabular}

\# These parameters were considered critical steps in IUD insertion 


\section{Appendix 4: Logical Steps to Assess the Knowledge of HCPs on IUD Removal}

\begin{tabular}{|c|c|c|}
\hline \multicolumn{3}{|c|}{ Selected parameters considered to assess the knowledge on IUD removal of HCPs } \\
\hline & Baseline (\%) & Endline (\%) \\
\hline 1. Counsel the client & 1.3 & $43.2 * * *$ \\
\hline 2. Prepare the client & 34.2 & $89.2 * * *$ \\
\hline 3. Gather all the equipments necessary for insertion & 32.8 & 41.9 \\
\hline 4. Wash your hands with soap and water ${ }^{\#}$ & 50.0 & $75.7 * * *$ \\
\hline 5. Put on clean/highly disinfected gloves ${ }^{\#}$ & 44.7 & $79.7 * * *$ \\
\hline 6. Clean clients external genitalia & 57.8 & 60.8 \\
\hline 7. Double check that instruments are ready & 0.0 & 10.8 \\
\hline 8. $\quad$ Insert sterile speculum & 76.3 & 79.7 \\
\hline 9. Localize cervix $^{\#}$ & 40.8 & 45.9 \\
\hline 10. Look for IUD thread and pull it out ${ }^{\#}$ & 86.8 & $95.9 *$ \\
\hline 11. Show the removed IUD to the clients ${ }^{\#}$ & 59.2 & $81.1 * * *$ \\
\hline 12. Put equipments into appropriate place & 6.5 & 8.1 \\
\hline 13. Wash your hands & 25.0 & 25.7 \\
\hline 14. Counsel the client about other contraceptive method & 53.9 & 68.9 \\
\hline Number of HCPs & 76 & 77 \\
\hline
\end{tabular}

\# These steps were considered critical in IUD removal. 


\section{Appendix 5: Parameters considered to Assess the Attitude of HCPs before and after Intervention}

\begin{tabular}{|c|c|c|}
\hline \multicolumn{3}{|c|}{ Selected parameters considered to assess the knowledge on IUD removal of HCPs } \\
\hline & Baseline (\%) & Endline (\%) \\
\hline 1. IUD can be used by newly married couples & 93.4 & 97.4 \\
\hline 2. IUD is a long-term contraceptive method & 40.8 & $83.1 * * *$ \\
\hline 3. One time insertion is required in the case of IUD & 17.1 & $50.6 * * *$ \\
\hline 4. IUD is suitable for most couples & 6.6 & $32.5 * * *$ \\
\hline 5. IUD is a very effective method & 47.4 & $80.8 * * *$ \\
\hline 6. IUD is alternate to sterilization & 6.2 & 13 \\
\hline 7. Would you recommend the IUD to a friend? & 98.7 & 98.7 \\
\hline 8. Would you / or your wife use IUD? & 31.6 & 40.3 \\
\hline Number of HCPS & 76 & 77 \\
\hline
\end{tabular}




\section{Appendix 6: Household Characteristics of Women in Study Population}

\begin{tabular}{|l|r|r|}
\hline Percentage distribution of households by selected housing characteristics, Vadodara \\
\hline & Baseline & Endline \\
\hline Total number of households & $\mathbf{8 9 4}$ & $\mathbf{8 8 0}$ \\
\hline Religion of head of the household & & \\
Hindu & 88.9 & 88.6 \\
Muslim & 9.7 & 9.2 \\
Others & 1.4 & 2.2 \\
\hline Caste of head of the household & & \\
Scheduled caste & 16.0 & 26.9 \\
Scheduled tribe & 9.2 & 11.9 \\
Other backward classes & 17.4 & 15.0 \\
Others & 56.8 & 45.6 \\
Don't know & 0.6 & 0.6 \\
\hline Type of house & & \\
Kachcha & 13.0 & 15.2 \\
Semi-pucca & 33.0 & 29.1 \\
Pucca & 54.0 & 55.7 \\
\hline Source of light & & \\
Electricity & 95.2 & 95.2 \\
Kerosene & 4.6 & 4.7 \\
\hline Source of drinking water & & \\
Tap water & 91.9 & 90.3 \\
Bore well & 6.7 & 9.0 \\
Others & 1.4 & 0.7 \\
\hline Source of cooking fuel & & \\
LPG & 52.9 & 55.6 \\
Kerosene & 10.4 & 10.5 \\
Wood & 36.1 & 31.9 \\
Others & 0.6 & 2.0 \\
\hline Type of toilet facility & 63.9 & 65.2 \\
Own flush toilet & 10.7 & 10.1 \\
Pit toilet & 3.0 & 1.7 \\
Shared toilet/public & 22.4 & 20.7 \\
No facility & & \\
& & \\
\hline
\end{tabular}




\section{Appendix 7: Parameters Considered to Assess Knowledge of Women before and after the Intervention}

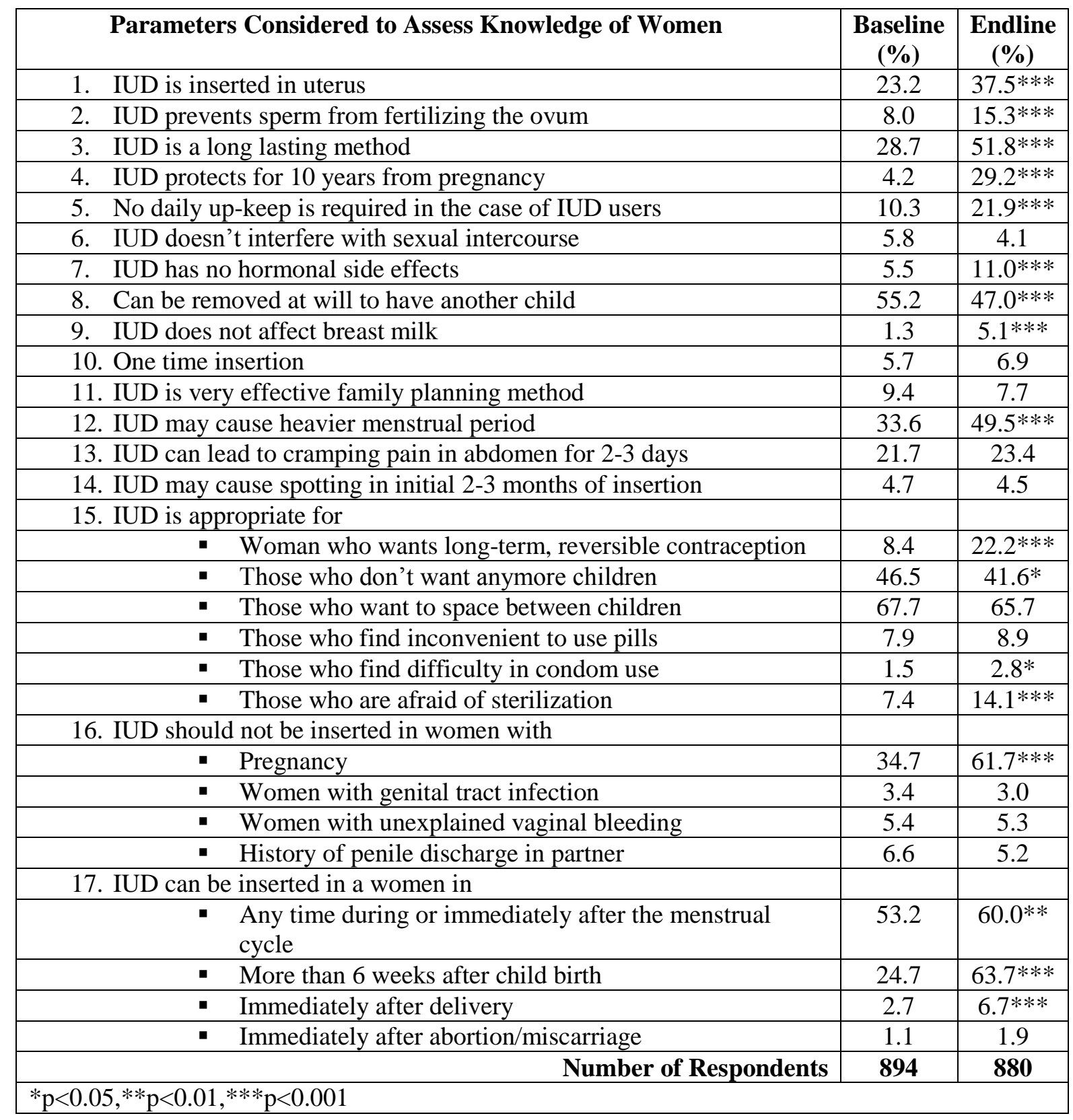




\section{Appendix 8: Background Characteristics of IUD Users}

\begin{tabular}{|l|c|c|}
\hline \multicolumn{3}{|c|}{$\begin{array}{c}\text { Percentage distribution of IUD users by selected background } \\
\text { characteristics, Vadodara }\end{array}$} \\
\hline Particulars & Baseline & Endline \\
\hline Total no. of IUD users & $\mathbf{8 3}$ & $\mathbf{2 0 5}$ \\
\hline Age (in years) & & \\
19 - 24 & 39.7 & 39.0 \\
25 - 29 & 39.8 & 35.6 \\
30 - 34 & 14.5 & 17.6 \\
35 or more & 6.0 & 7.8 \\
Mean age in years & 25.9 & 26.5 \\
\hline Education level & & \\
Illiterate & 13.3 & 11.2 \\
Up to primary (1-5) & 8.4 & 4.3 \\
Up to high school (6-10) & 48.2 & 44.8 \\
Higher secondary or above & 30.1 & 39.7 \\
\hline Occupation & & \\
Working for cash/kind & 8.4 & 15.6 \\
Not-working & 91.6 & 84.4 \\
\hline Average monthly income (in rupees) & 1314 & 1270 \\
\hline Religion & & \\
Hindu & 91.6 & 81.0 \\
Muslim & 8.4 & 17.1 \\
\hline Caste & & \\
Scheduled caste & 6.0 & 19.5 \\
Other backward caste & 12.0 & 16.1 \\
Others & 82.0 & 53.7 \\
\hline
\end{tabular}




\section{Appendix 9: Assessment of Quality of IUD Services by Interviewing IUD}

Acceptors

\begin{tabular}{|c|c|c|}
\hline \multicolumn{3}{|c|}{ Parameters Considered to Assess the Quality of IUD Services by Interviewing IUD Acceptors } \\
\hline Pre-insertion Counseling & Baseline & Endline \\
\hline a. What is IUD? & 74.7 & $92.7^{\star * *}$ \\
\hline b. Who should use IUD? & 68.7 & $88.8^{* * *}$ \\
\hline c. How IUD works, (prevents sperm and egg from meeting)? & 24.1 & $59.0^{* * *}$ \\
\hline d. Side effects of IUD are minor and lasts for a short period & 74.7 & $86.3^{\star *}$ \\
\hline e. Can be removed at will to have another child & 97.6 & 98.0 \\
\hline f. Does not cause any discomfort during sex & 66.3 & 73.7 \\
\hline g. IUD doesn't cause weight gain & 49.4 & $73.3^{* * *}$ \\
\hline h. IUD doesn't cause infertility & 43.4 & $68.3^{* * *}$ \\
\hline i. IUD can be used by women who have had a caesarean section & 50.6 & 61.0 \\
\hline I. Was IUD shown to you? & 83.1 & $94.1^{\star \star}$ \\
\hline m. Were you told to bring your husband for the next counseling session? & 27.7 & $59.0^{\star * *}$ \\
\hline \multicolumn{3}{|l|}{ Maintenance of Privacy During the Procedure } \\
\hline a. Whether auditory privacy was maintained during the discussion & 79.5 & $90.7^{* *}$ \\
\hline b. Whether visual privacy was maintained during the insertion & 94.0 & 98.5 \\
\hline c. Were all your doubts and questions about the IUD answered & 97.6 & 98.5 \\
\hline \multicolumn{3}{|l|}{ Screening of Clients } \\
\hline \begin{tabular}{|l} 
a. Before inserting IUD did the provider ensure that \\
$-\quad$ You are currently not pregnant \\
- You don't have history of foul smelling discharge from genital \\
- tract \\
\end{tabular} & $\begin{array}{l}94.0 \\
71.1 \\
42.2\end{array}$ & $\begin{array}{c}86.3 \\
93.2^{\star * *} \\
75.1\end{array}$ \\
\hline \begin{tabular}{|l} 
b. Before insertion of IUD whether the following examinations were \\
conducted \\
- Hemoglobin \\
$:$ Examination of eye/ conjunctiva \\
$:$ Pelvic or internal examination \\
- Pregnancy test \\
\end{tabular} & $\begin{array}{l}21.7 \\
20.5 \\
72.3 \\
50.6 \\
33.7\end{array}$ & $\begin{array}{l}24.9 \\
30.2 \\
77.1 \\
66.8^{* *} \\
52.2^{* *}\end{array}$ \\
\hline c. Did the health care provider use any checklist for screening? & 2.4 & $47.8^{\star \star \star}$ \\
\hline d. Was any IEC material used during the counseling session? & 9.6 & $55.6^{* * *}$ \\
\hline
\end{tabular}




\begin{tabular}{|c|c|c|}
\hline \multicolumn{3}{|l|}{ Infection Prevention Practices } \\
\hline a. Were you asked to urinate & 92.8 & 97.6 \\
\hline b. Whether provider washed their hands with soap prior to actual insertion & 94.0 & $99.5^{\star *}$ \\
\hline c. Did the provider wear gloves at the time of insertion & 100 & 100 \\
\hline d. Whether your external genitalia was cleaned & 90.4 & $98^{* *}$ \\
\hline \multicolumn{3}{|l|}{ Follow up advice } \\
\hline a. IUD is immediately effective after insertion & 72.3 & $86.6^{\star *}$ \\
\hline b. There might be slight bleeding or spotting for a week & 86.7 & 89.3 \\
\hline c. There might be pain in lower part of abdomen in the first 48 hours & 92.8 & 91.2 \\
\hline d. How to check the string of the IUD & 62.7 & $80.0^{* *}$ \\
\hline e. Advice regarding follow-up was given & 97.6 & 95.1 \\
\hline f. $\quad$ Provided with any IEC material about IUD for reading & 15.7 & $74.6^{* * \star}$ \\
\hline Number of Respondent & 83 & 205 \\
\hline
\end{tabular}

${ }^{*} \mathrm{p}<0.05, * * \mathrm{p}<0.01, * * * \mathrm{p}<0.001$ 